\title{
Characterization and Modeling of DHBT in InP/GaAsSb Technology for the Design and Fabrication of a Ka Band MMIC Oscillator
}

\author{
S. Laurent, ${ }^{1}$ J. C. Nallatamby, ${ }^{1}$ M. Prigent, ${ }^{1}$ M. Riet, ${ }^{2}$ and V. Nodjiadjim ${ }^{2}$ \\ ${ }^{1}$ XLIM-High Frequency Components, Circuits, Signals and System Department (C2S2), Université de Limoges, 7 rue Jules Vallés, \\ 19100 Brive, France \\ ${ }^{2}$ III-V Lab, Joint Lab between Bell Labs, TRT and CEA/Leti, Route de Nozay, 91460 Marcoussis, France
}

Correspondence should be addressed to M. Prigent, michel.prigent@xlim.fr

Received 13 September 2011; Accepted 18 November 2011

Academic Editor: Christoph Sandner

Copyright () 2012 S. Laurent et al. This is an open access article distributed under the Creative Commons Attribution License, which permits unrestricted use, distribution, and reproduction in any medium, provided the original work is properly cited.

\begin{abstract}
This paper presents the design of an MMIC oscillator operating at a $38 \mathrm{GHz}$ frequency. This circuit was fabricated by the III-V $\mathrm{Lab}$ with the new InP/GaAsSb Double Heterojunction Bipolar Transistor (DHBT) submicronic technology $($ We $=700 \mathrm{~nm}$ ). The transistor used in the circuit has a $15 \mu \mathrm{m}$ long two-finger emitter. This paper describes the complete nonlinear modeling of this DHBT, including the cyclostationary modeling of its low frequency (LF) noise sources. The specific interest of the methodology used to design this oscillator resides in being able to choose a nonlinear operating condition of the transistor from an analysis in amplifier mode. The oscillator simulation and measurement results are compared. A $38 \mathrm{GHz}$ oscillation frequency with $8.6 \mathrm{dBm}$ output power and a phase noise of $-80 \mathrm{dBc} / \mathrm{Hz}$ at $100 \mathrm{KHz}$ offset from carrier have been measured.
\end{abstract}

\section{Introduction}

The developments in modern electronics (analog, digital, or mixed), whatever their intended applications (telecommunications, spectroscopy and astrophysics, plasma analysis, medical imaging, etc.) now concern applications operating from RF frequency spectrum up to the optical frequencies. In order to develop solid-state circuits operating in the millimeter wave range, new technological processes are emerging for manufacturing semiconductors operating in these domains. To achieve the performances required by such applications, a suitable solid-state technology must be available. III-V Lab provides a new InP/GaAsSb DHBT technology [1], which contains antimony in the base of the transistors and permits submicronic emitter sizes. The structure has been optimized to get an $F_{\max }$ greater than $300 \mathrm{GHz}$ and an $F_{T}$ equal to $200 \mathrm{GHz}$. In this context, the work presented in this paper demonstrates the feasibility of designing and manufacturing a low phase noise MMIC frequency source with this new technology. To provide the oscillator designer with the most relevant devices, various multifinger transistors have been measured, a number ranging from 2 to 8 have been compared and reported in [2]. For the higher-frequency applications, 2-finger devices were found to be best suited and selected for this design. In Section 2, we present the complete characterization and nonlinear modeling of the transistor, including its thermal behavior. Section 3 deals with the cyclostationary LF noise source modeling. Section 4 is devoted to the description of the oscillator design according to the new proposed methodology including the drawing of the MMIC layout. In Section 5, all the measurements are detailed and compared with the results predicted by the simulation. The last section concludes the article.

\section{Transistor Modeling}

In order to design oscillators with improved characteristics, we need accurate models of the passive and active elements of these circuits. The models of passive elements of this process fabricated on coplanar waveguide technology (CPW) have been developed by the MC2 Technology Company. The 


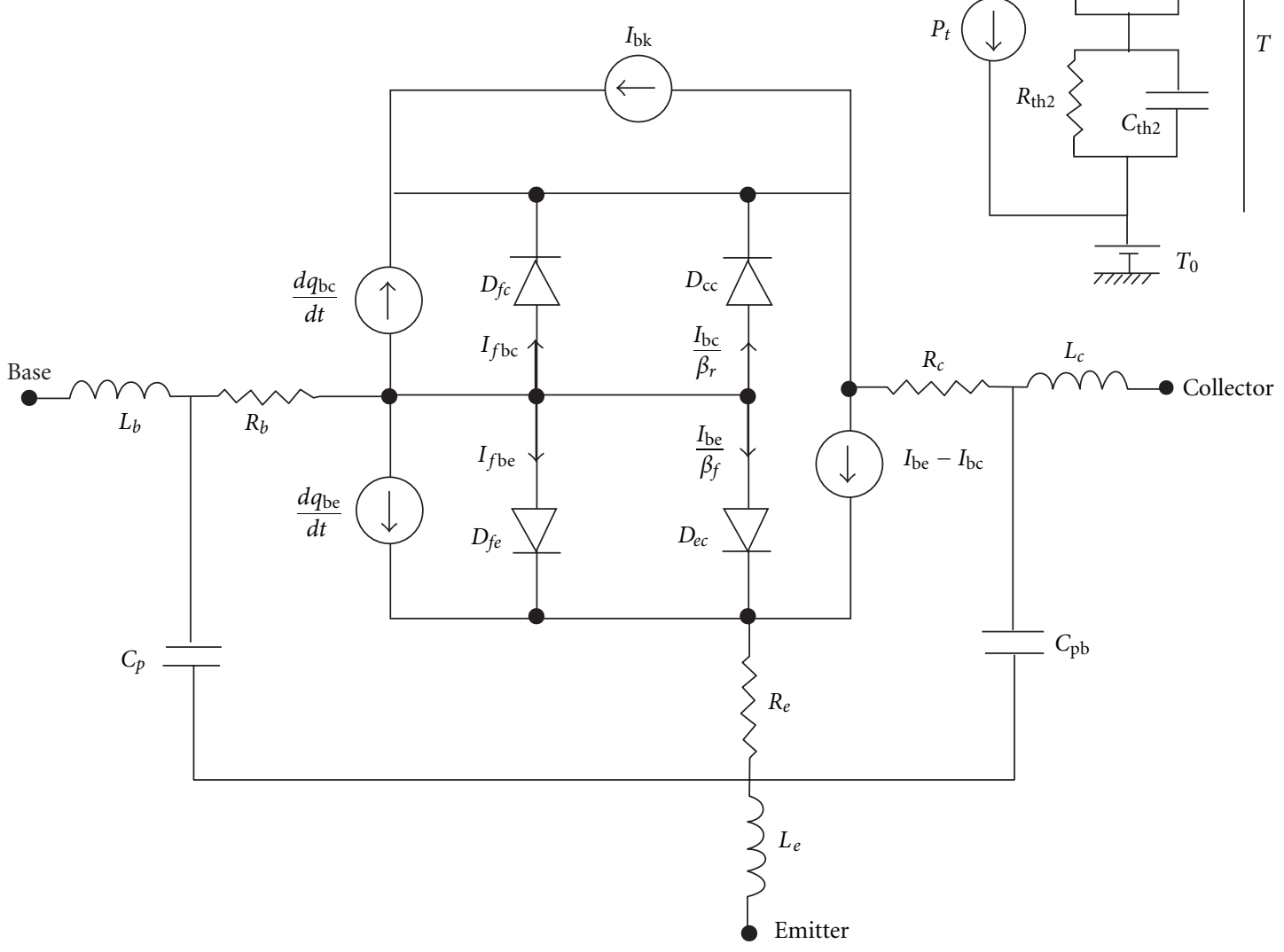

FIgURE 1: DHBT model $\pi$-topology with a two-pole RC thermal subcircuit.

DHBT $\pi$ model is based on the Gummel and Poon model [3] improved in [4]. It is presented in Figure 1 with its associated thermal circuit formed by two-pole RC cells. The intrinsic part of the convective equivalent circuit is described by four diodes and one voltage-controlled current source: $D_{\mathrm{ec}}$ and $D_{\mathrm{cc}}$ control the current source with, respectively, a direct gain $\beta_{f}$ and a reverse gain $\beta_{r}, D_{f e}$, and $D_{f c}$ model leakage currents. The base collector charge $q_{\mathrm{bc}}$ results from the sum of the junction charge with "punchthrough effect" charge, and the depletion charge. The base emitter charge $q_{\text {be }}$ results from the sum of three charges: the junction charge, the depletion charge due to the collector transit time, and the Kirk effect charge. These charges depend on the $V_{\text {ce }}$ and $V_{\text {be }}$ voltages. The extraction of parameters describing the non linear transistor model is performed from pulsed I-V, pulsed $[S]$-parameters measurements. More details on this currently conventional operation are given in $[5,6]$. Note that this paper is a detailed version of [7] in which we will explain all the measurement and extraction procedure for the modeling and the design methodology of the oscillator.

To determine the thermal circuit elements, the new method proposed here is a good trade-off between speed and accuracy. This method involves the determination of the impedance and thermal time constant from the measurement of the transistor input impedance at low frequencies.
Indeed, the thermal resistance can be estimated from the input impedance $Z_{\mathrm{BE}}$ by (2):

$$
\begin{aligned}
Z_{\mathrm{BE}} & =\frac{V_{\mathrm{BE}}}{I_{B}} \\
& =h_{11_{\mathrm{ISO}}}+\phi \cdot Z_{\mathrm{TH}}(\omega) \cdot h_{21} \cdot\left(V_{\mathrm{CE}_{0}}-R_{2} \cdot I_{C_{0}}\right),
\end{aligned}
$$

with

$$
\phi=\left.\frac{\partial V_{\mathrm{BE}}}{\partial T}\right|_{I_{B}=\mathrm{CTE}},
$$

where $V_{\mathrm{BE}}$ and $I_{B}$ are HBT Base-Emitter voltage and base current, $h_{11_{\text {ISO }}}$ is the $h_{11}$ isothermal parameter, $Z_{\mathrm{TH}}$ is the thermal impedance, $V_{\mathrm{CE}_{0}}$ and $I_{C_{0}}$ are the bias CollectorEmitter voltage and Collector current, $R_{2}$ is the load resistance on the collector (see Figure 2).

So, according to this equation, we must determine the $\phi, h_{21}$, and $h_{11_{\text {Iso }}}$ parameters to deduce the thermal impedance $Z_{\mathrm{TH}}$. The $\phi$ parameter is determined using the $I_{b}$ measurement as a function of $V_{\text {be }}$ for a constant current $I_{c}$ at different temperatures in DC mode. The methodology is detailed in [8]. The $h_{21}$ parameter is determined using the following four quantities shown in Figure 2 where $Z_{\text {in }}$ is the input impedance, $Z_{\text {out }}$ is the output impedance, $Z_{\mathrm{in}_{0}}$ is the input impedance when the transistor output is 

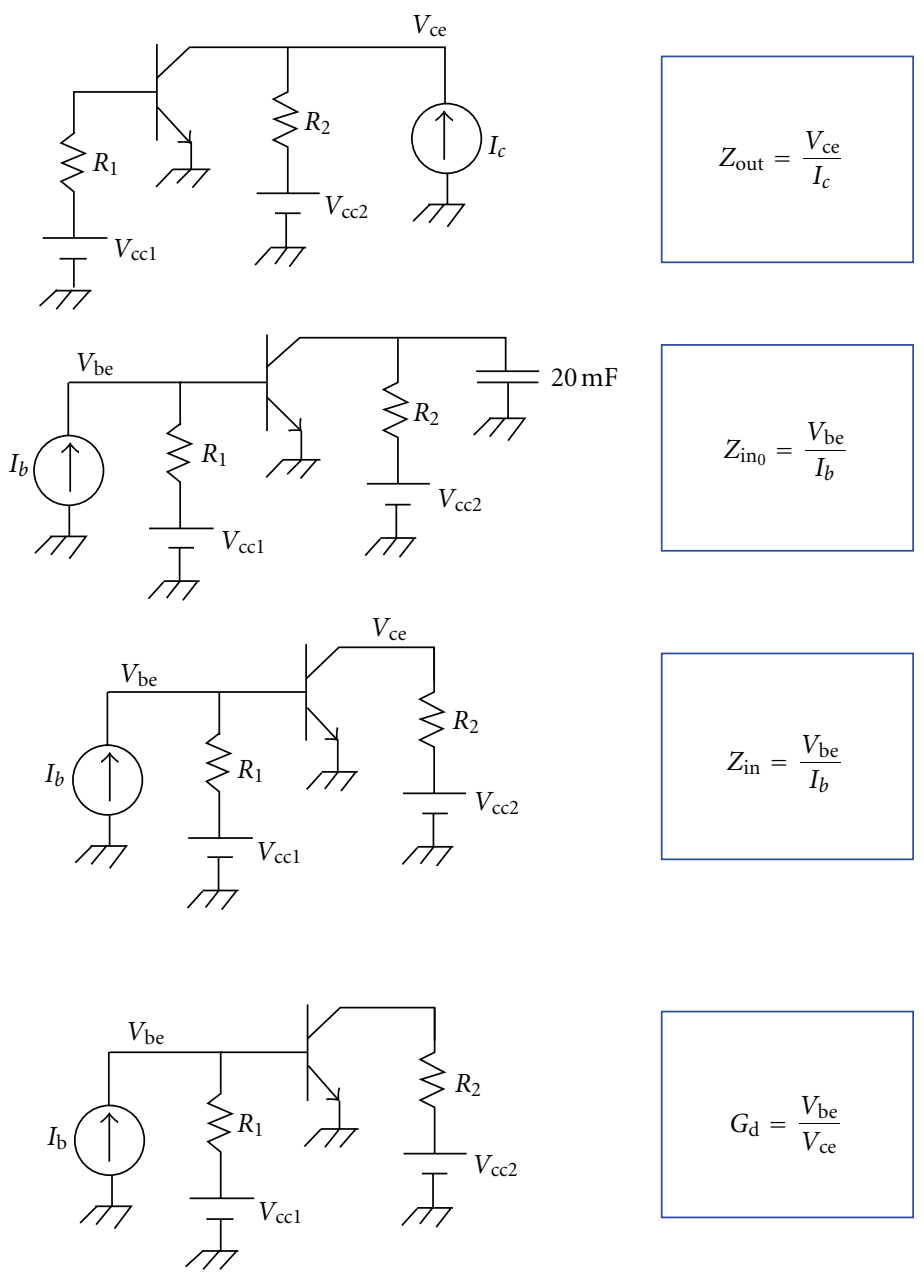

FIGURE 2: Measurements used to determine the $h_{21}$ parameter.

short circuited at LF, and $G_{d}$ is the transistor voltage gain. Thus, it is possible to extract the $h_{21}$ parameter from these four measures by using the hybrid equivalent circuit of the transistor, and with (3) [9]:

$$
h_{21}=\frac{Z_{\text {in }} \cdot G_{d} \cdot R_{1}}{Z_{\text {out }}\left(Z_{\text {in }_{0}}-R_{1}\right)},
$$

where $R_{1}$ is the base resistance (see Figure 2). The $h_{11_{150}}$ parameter is determined by measuring the transistor input impedance with $R_{2}=V_{\mathrm{ce}_{0}} / I_{c_{0}}$. In this case, the measured impedance is defined by $Z_{\mathrm{BE}}=h_{11_{\mathrm{ISO}} \mathrm{O}}$. At last, the input impedance is measured with a resistor $R_{2}$ different from the previous value, but at the same bias point (Figure 3 ). Knowing the parameters of the equation, we can deduce the thermal impedance $Z_{\text {th }}$. To implement this self-heating effect in a simulator, we include a low-pass equivalent electrical circuit with two RC parallel cells in series whose impedance fits the measured $Z_{\mathrm{th}}$. Thus, it is possible to obtain an equivalence between voltage/temperature and current/power as shown in Figure 3.

To conclude this first modeling step, we compare the convective model simulation with measurements. For example, Figure 4 shows the comparison of the $I_{c}\left(V_{c e}\right)$ network, the current gain $\beta$ as a function of $V_{\text {ce }}$ and $V_{\text {be }}$ versus $V_{\text {ce }}$ for an $I_{b}$ current range from $0.5 \mathrm{~mA}$ to $3 \mathrm{~mA}$ in steps of $0.5 \mathrm{~mA}$ at a temperature equal to $25^{\circ} \mathrm{C}$.

The last modeling step is the determination of the nonlinear charges $q_{\mathrm{bc}}$ and $q_{\mathrm{be}}$ by means of the pulsed [S] parameters measurements. The final modeling verification consists in comparing the complete electrothermal nonlinear model simulation with measurement. Figure 5 shows the comparison between simulation and measurement of the $[S]$ parameters, the maximum available gain (MAG) and $h_{21}$ parameter versus frequency for a $I_{b}$ current equal to $2 \mathrm{~mA}$ and $V_{\text {ce }}$ voltage equal to 1,2 , and $2.5 \mathrm{~V}$. Thus, we get a good agreement between the two results.

\section{Modeling of Transistor Low-Frequency Noise Sources}

An accurate prediction of oscillator phase noise requires a cyclostationary model of the LF noise sources of the transistor [10]. A transistor model with internal LF noise sources [11] with cyclostationary properties has been developed for a GaInP/GaAs HBT technology. This model is only based on low-frequency measurements around DC bias. The noise 


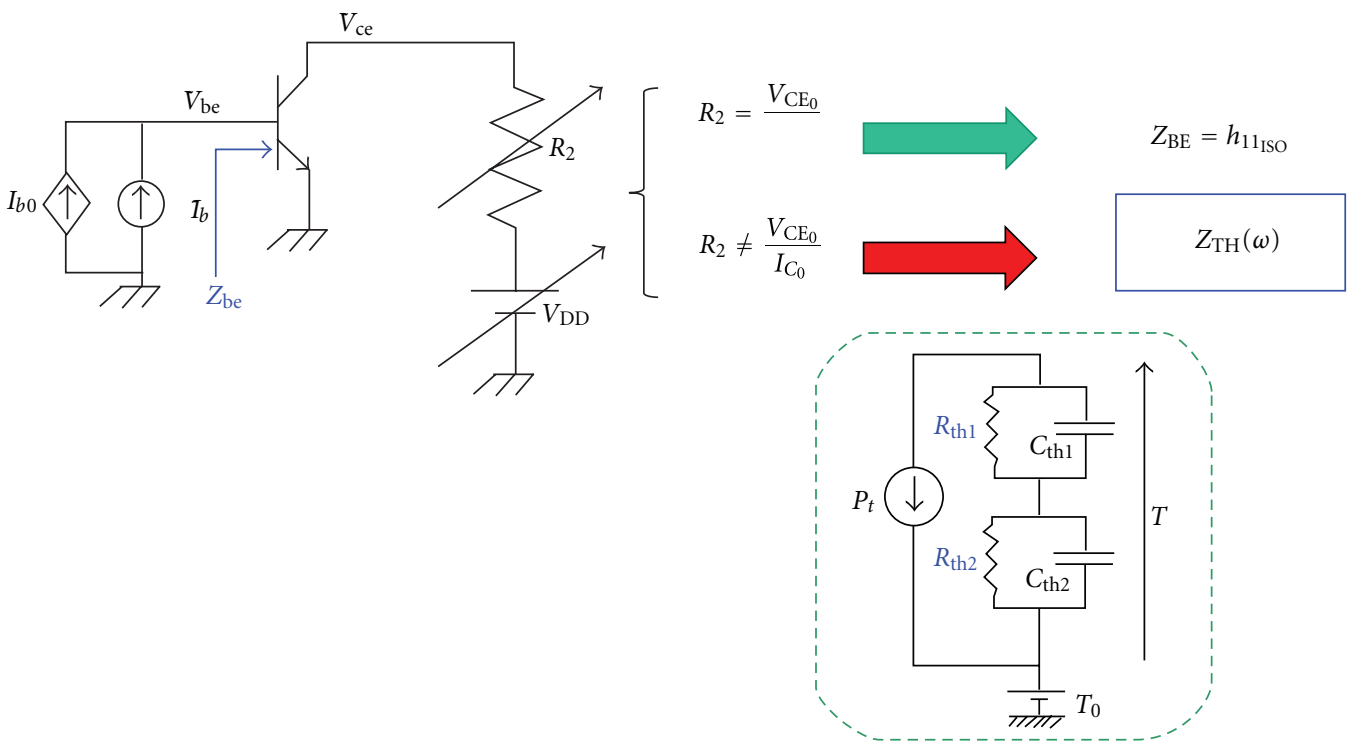

FIgURe 3: Determination of thermal impedance.

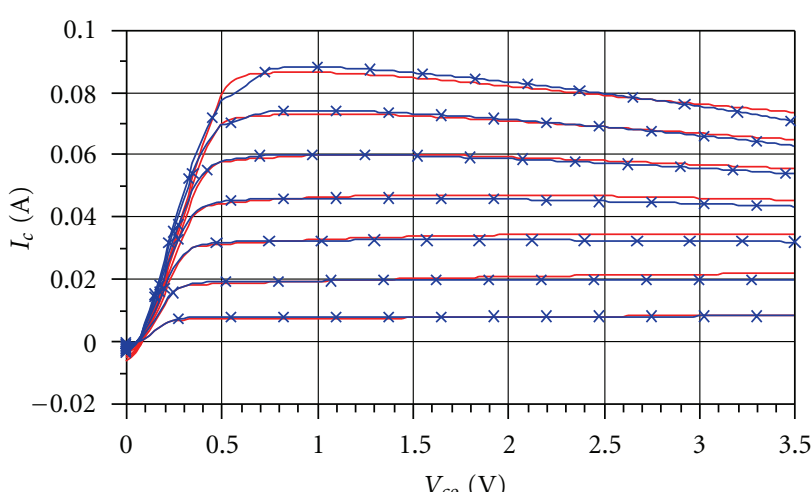

— Measurement

- Simulation

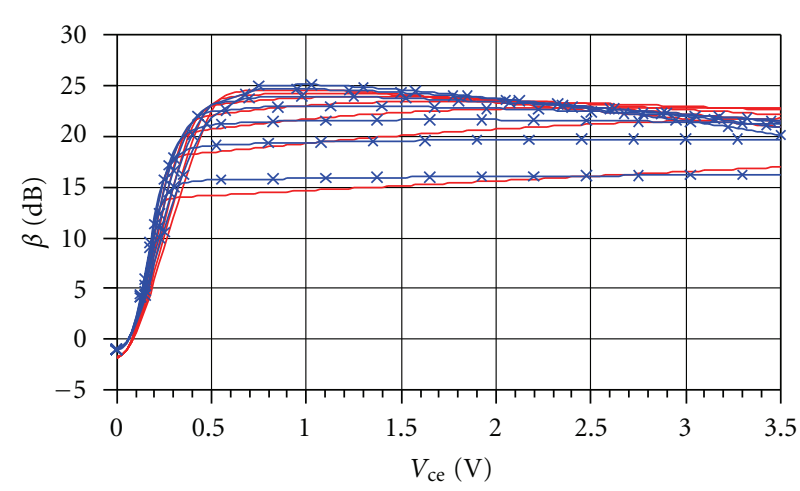

— Measurement

- Simulation

(a)

(b)

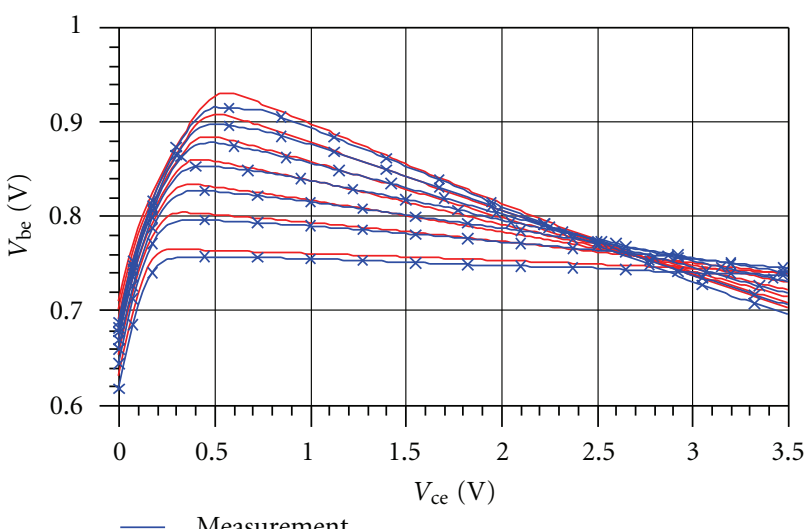

Simulation

(c)

Figure 4: Comparison between model (red) and $\mathrm{I}(\mathrm{V})$ measurement (blue cross) with $I_{b}$ current ranging 0.5 to $3.5 \mathrm{~mA}$ and a $V_{\text {ce }}$ voltage ranging 0 to $3.5 \mathrm{~V}$ for a temperature equal to $25^{\circ} \mathrm{C}$. 


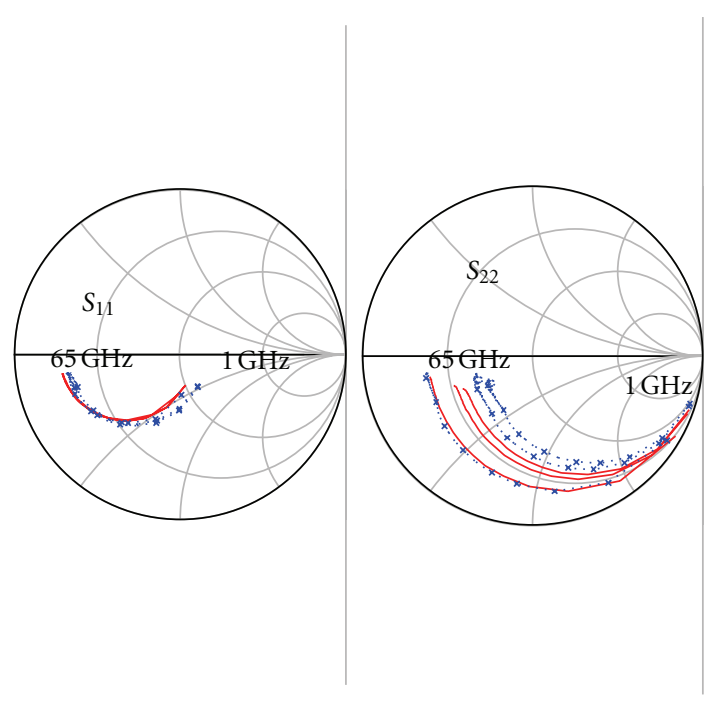

(a)
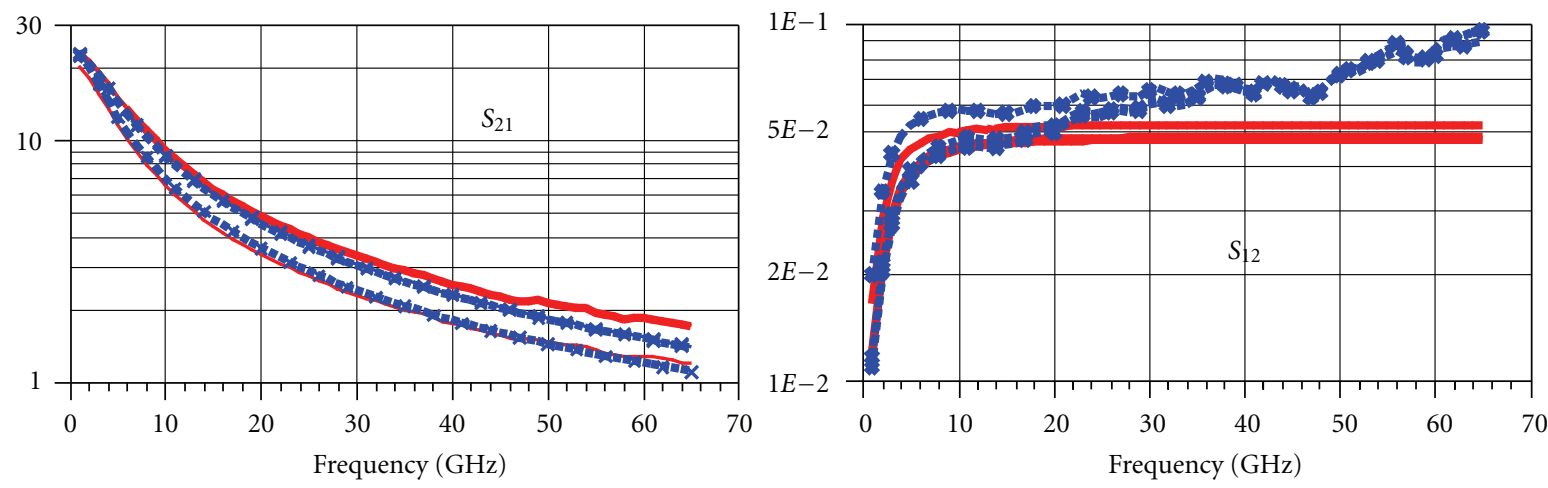

(b)
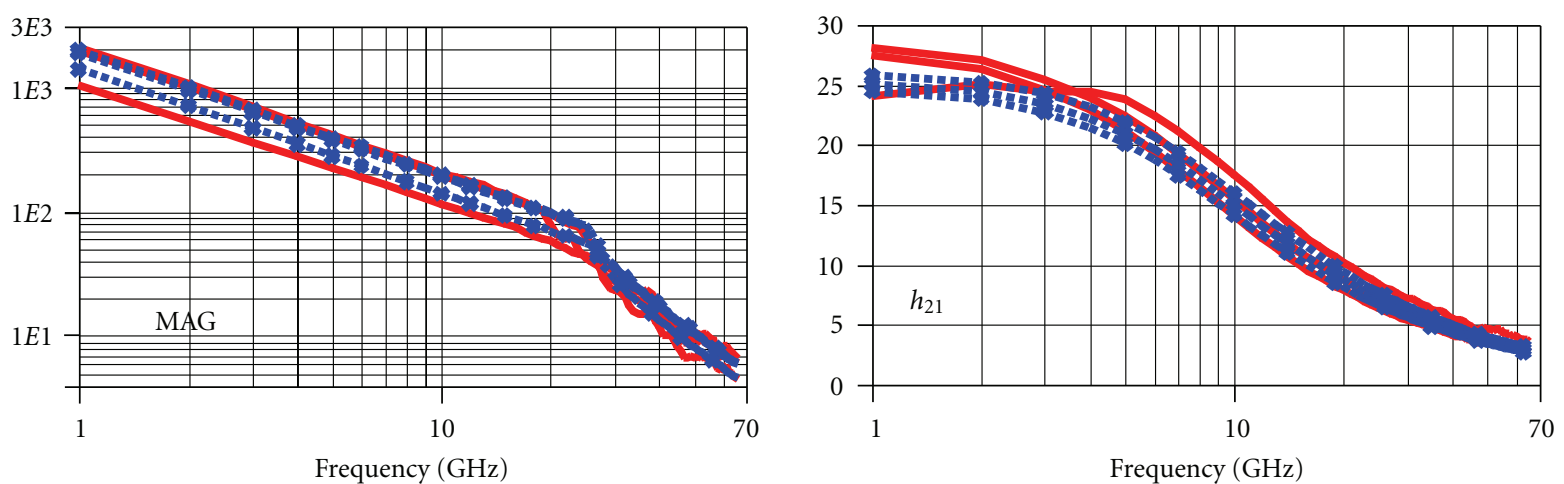

(c)

FIGURE 5: Comparison between model simulation results in red and measurements (blue cross) for the MAG, $S_{11}, S_{12}, S_{22}, S_{21}$, and $h_{21}$ parameters with $I_{b}=2 \mathrm{~mA}$ and $V_{\text {ce }}=1-2-2.5 \mathrm{~V}$.

sources variations versus the DC collector current are taken into account to elaborate cyclostationary noise model. We propose to reuse this topology (Figure 6) for this InP/GaAsSb technology with the new extraction method presented here.

This LF model of the transistor (the nonlinear charges are not represented here) is based on the original representation of Ebers and Moll (Model T), called injection model, which is based on current-controlled current sources. He directly comes from the equations of physics and models the injection currents of the transistor. $\alpha$ is the large-signal forward mode current gain of a common-base transistor. More details on its equivalence to the Gummel-Poon model are given in [12]. Moreover, the extraction of noise sources from measurement is easier with this model. The diode 


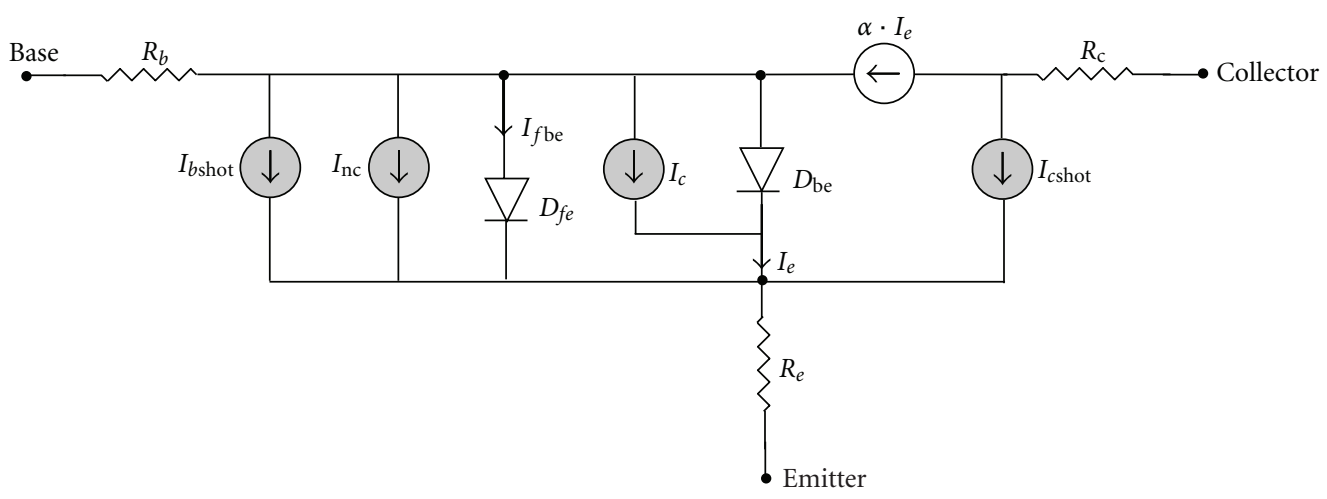

FIgURE 6: LF equivalent circuit of the transistor with noise sources.

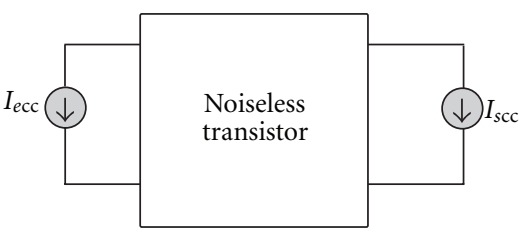

(a)

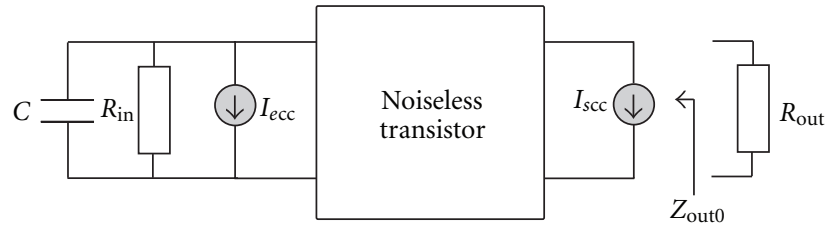

(b)

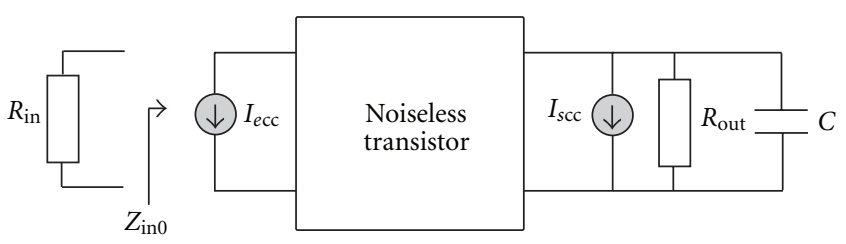

(c)

FIGURE 7: Equivalent circuit of a noisy transistor with current noise sources.

$D_{\text {be }}$ represents the base-emitter junction, $D_{f e}$ represents the leakage current of the base-emitter junction. The transistor effect is modeled by the controlled current source $\alpha \cdot I_{e}$. The current sources $I_{c \text { shot }}$ and $I_{b \text { shot }}$ are the shot noise sources, $I_{c}$ and $I_{\mathrm{nc}}$ represent the LF noise sources ( $1 / f$ and GR). The thermal noise sources of access resistors are negligible. The noise source $I_{c}$ is generated within the base-emitter junction and it is associated to the $D_{\mathrm{eb}}$ diode. It participates in the transistor effect through the controlled current source $\alpha \cdot I_{e}$. The origin of the $I_{\mathrm{nc}}$ source comes from the periphery of the base-emitter junction and can be associated with the leakage diode $D_{f e}$. This representation with only two LF sources results from many measurements and simulations of oscillators which have shown that this transistor model is sufficient to accurately simulate oscillator phase noise. The purpose of the modeling is to extract the sources $I_{c}$ and $I_{\mathrm{nc}}$ from noise measurement. In order to do that, we suppose that the transistor low-level model with its noise sources can be represented by the conventional schema of Figure 7(a) with a Norton equivalent current source at each access of the transistor. Noise measurements consist in successively measuring these two noise sources $I_{\mathrm{ecc}}$ and $I_{\mathrm{scc}}$. To do that, two low value resistances $R_{\text {in }}$ and $R_{\text {out }}$, properly chosen $\left(R_{\text {in }} \ll Z_{\text {in }_{0}}\right.$ and $\left.R_{\text {out }} \ll Z_{\text {out }_{0}}\right)$, are successively connected to each access in order to short-circuit the corresponding source [13]. Moreover, to achieve this condition, a huge capacitance is successively connected to the transistor access (in parallel with $R_{\text {in }}$ or $R_{\text {out }}$ of Figure 7(b) and 7(c)) where we do not measure the noise. The voltage thus generated is then amplified by the voltage amplifier and its output is connected to the FFT spectrum analyzer in order to measure the noise voltage spectral density.

The schema used to obtain the noise sources of the transistor accesses is presented in Figure 8.

This schema is the same at each access of the transistor. The amplifier is represented by its noise voltage source $e_{\text {at }}$ and by its input impedance $Z_{\text {at }}$. The voltage $V_{s}$ is amplified with a gain $G$ to be measured on the FFT analyzer. The [ABCD] matrix represents all the passive elements considered in the measurement (bias tees, lines, etc.). $R$ can be either $R_{\text {in }}$ or $R_{\text {out }}, I_{R}$ is the thermal current noise source associated to $R$, $I_{\text {dut }}$ can be either $I_{\mathrm{ecc}}$ or $I_{\mathrm{scc}}$, and $Z_{\text {dut }}$ can be either $Z_{\mathrm{in}_{0}}$ (with the collector short-circuited) or $Z_{\text {out }_{0}}$ (with the base shortcircuited). Thus, applying Kirchoff's laws, we obtain (4):

$$
V_{s}=\frac{N_{2} \cdot I_{\mathrm{dut}}+N_{3} \cdot e_{\mathrm{at}}+N_{4} \cdot I_{R}}{N_{1}},
$$




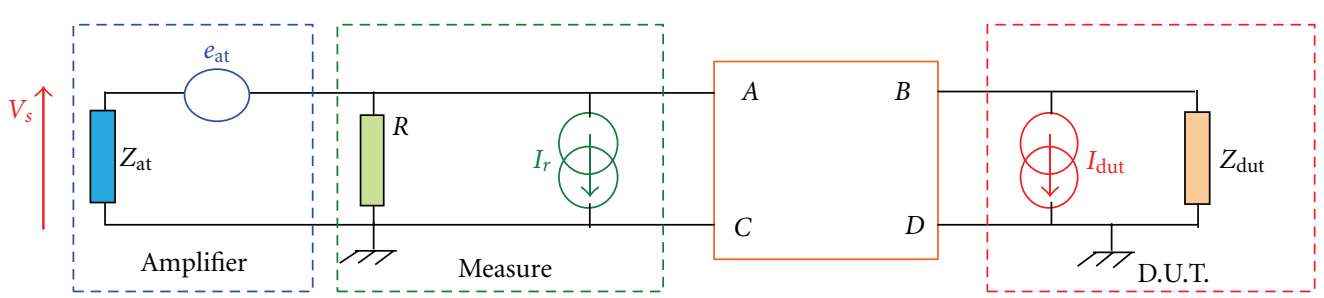

Figure 8: Equivalent schema for the extraction of short-circuit noise current spectral density at transistor accesses.
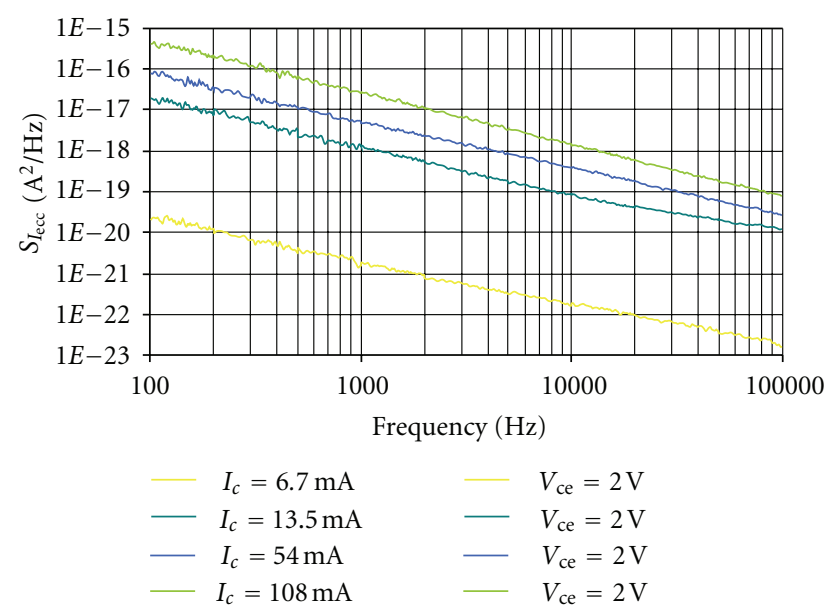

(a)

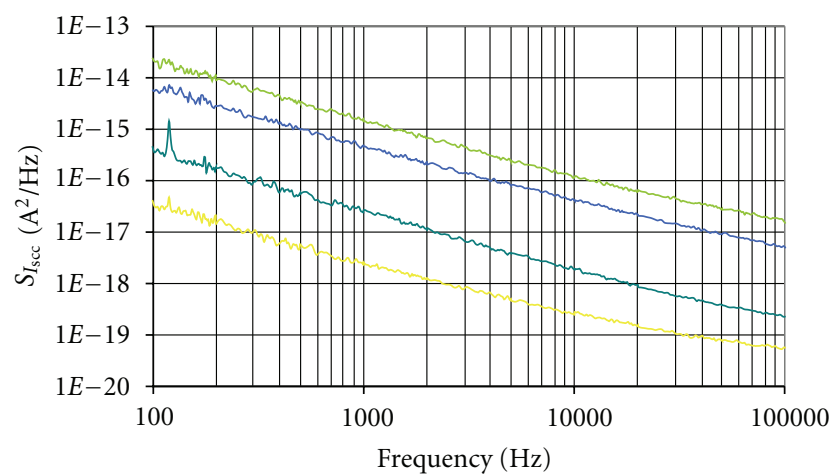

$$
\begin{array}{rlr}
I_{c}=6.7 \mathrm{~mA} & -V_{\mathrm{ce}}=2 \mathrm{~V} \\
-I_{c}=13.5 \mathrm{~mA} & -V_{\mathrm{ce}}=2 \mathrm{~V} \\
-I_{c}=54 \mathrm{~mA} & -V_{\mathrm{ce}}=2 \mathrm{~V} \\
-I_{c}=108 \mathrm{~mA} & -V_{\mathrm{ce}}=2 \mathrm{~V}
\end{array}
$$

(b)

FIGURE 9: Spectral densities plot of the short-circuit noise current at transistor access for collector currents $I_{c_{0}}=6.7,13.5,54,108 \mathrm{~mA}$.

Now, we must determine the noise voltage spectral densities at each access:

$$
S_{V_{s}}=\left|\frac{N_{2}}{N_{1}}\right|^{2} S_{I_{\mathrm{dut}}}+\left|\frac{N_{3}}{N_{1}}\right|^{2} S_{e_{\mathrm{at}}}+\left|\frac{N_{4}}{N_{1}}\right|^{2} S_{I_{R}}
$$

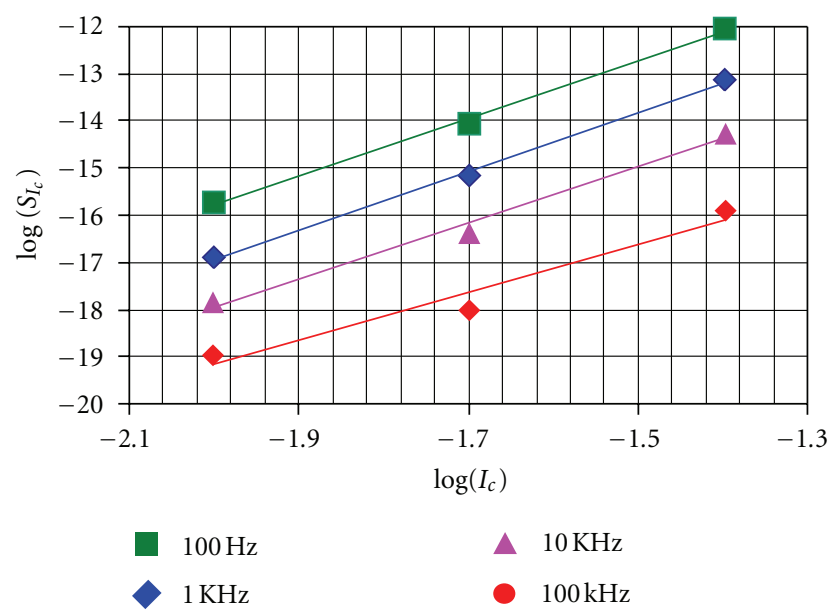

(a)
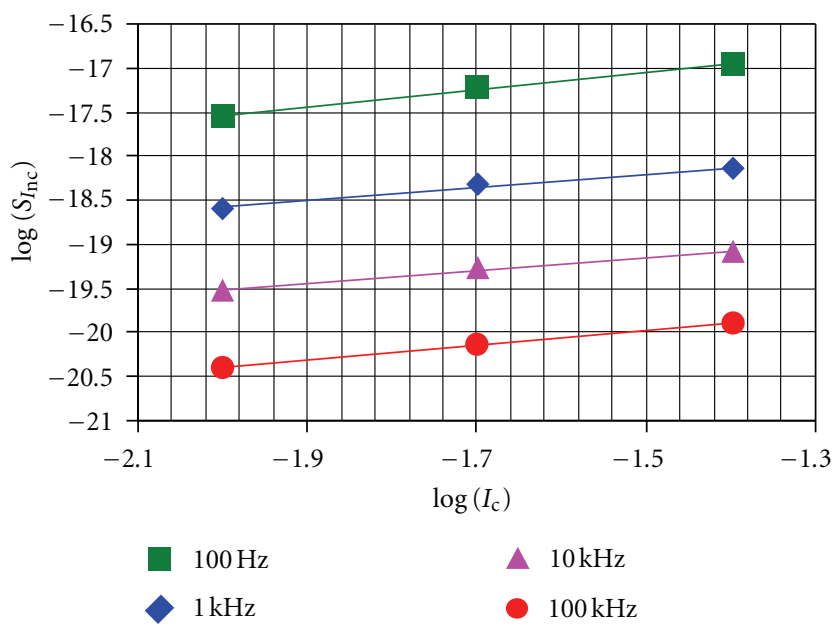

(b)

Figure 10: Plot of $S_{\mathrm{ic}}$ and $S I_{\mathrm{nc}}$ noise current spectral densities.

with

$$
\begin{aligned}
N_{1}= & Z_{\mathrm{at}} \cdot R \cdot D+Z_{\mathrm{at}} \cdot R \cdot Z_{\mathrm{dut}} \cdot C+Z_{\mathrm{polar}} \cdot Z_{\mathrm{dut}} \cdot A \\
& \quad+R \cdot B+Z_{\mathrm{at}} \cdot Z_{\mathrm{dut}} \cdot A+Z_{\mathrm{at}} \cdot B, \\
N_{2}= & Z_{\mathrm{at}} \cdot Z_{\mathrm{dut}} \cdot R \cdot(A \cdot D-B \cdot C), \\
N_{3}= & Z_{\mathrm{at}} \cdot\left(-R \cdot D-R \cdot Z_{\mathrm{dut}} \cdot C-Z_{\mathrm{dut}} \cdot A-B\right), \\
N_{4}= & Z_{\mathrm{at}} \cdot\left(Z_{\mathrm{dut}} \cdot R \cdot A+R \cdot B\right) .
\end{aligned}
$$




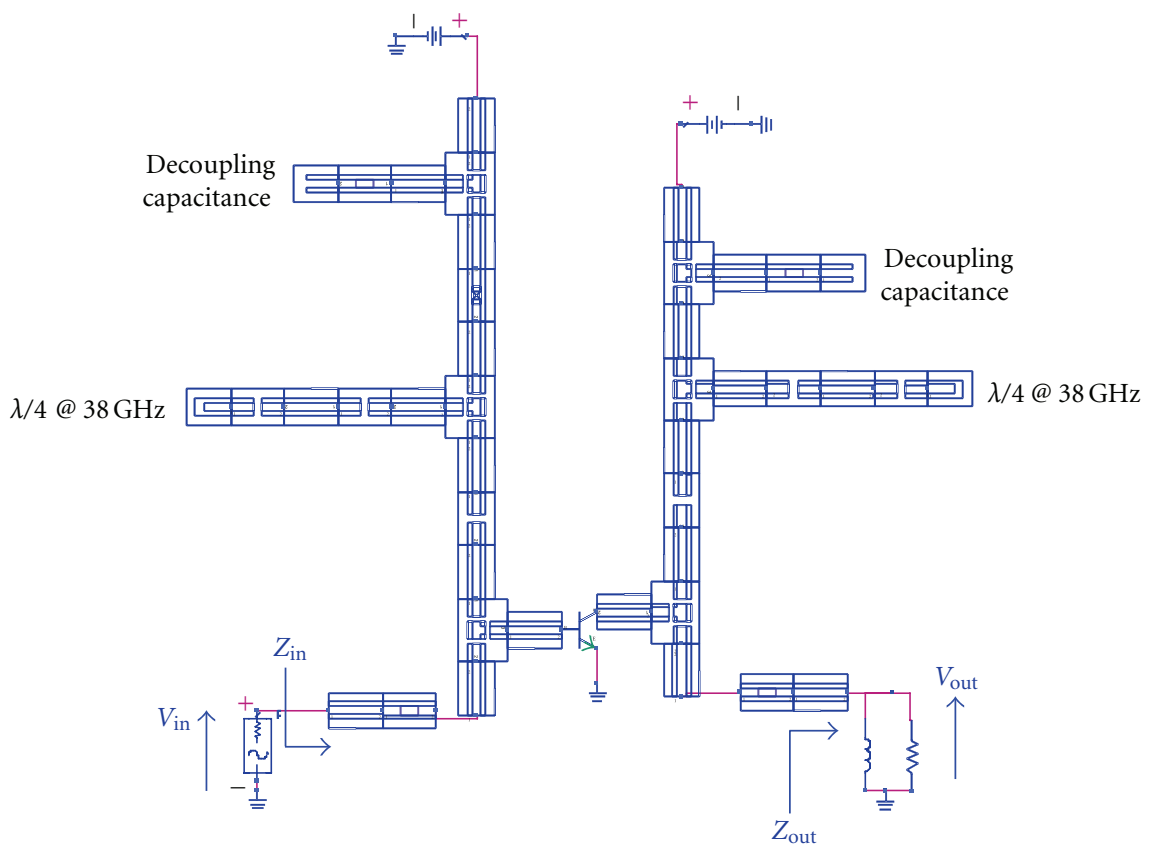

FIGURE 11: Circuit for nonlinear amplifier simulation.

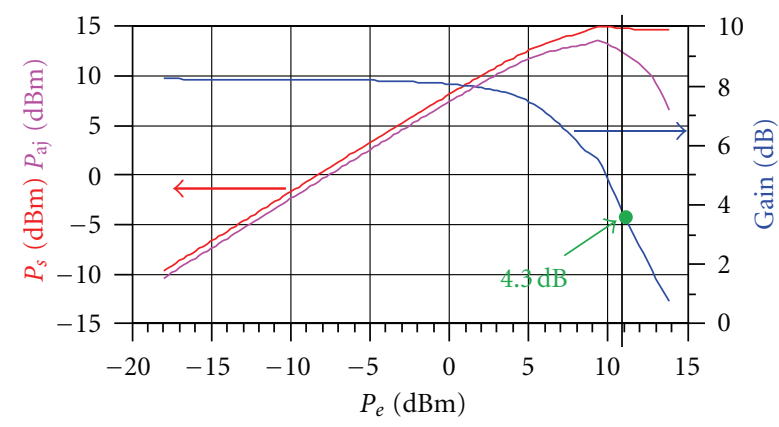

Figure 12: Amplifier simulation results.

Now, we can define the short-circuit noise current spectral density, which is expressed by the following equation:

$$
S_{I_{\mathrm{dut}}}=\left|\frac{N_{1}}{N_{2}}\right|^{2} S_{V_{s}}-\left|\frac{N_{4}}{N_{2}}\right|^{2} S_{I_{R}}-\left|\frac{N_{3}}{N_{2}}\right|^{2} S_{e_{\mathrm{at}}} .
$$

From the previous equation applied to each access of the transistor, we thereby obtain the expressions of the noise current spectral densities $S_{I_{\text {ecc }}}$ or $S_{I_{\text {scc }}}$. The last step of this noise modeling consists in extracting the two internal noise sources spectral densities $S_{I_{c}}$ and $S_{I_{\mathrm{nc}}}$ in Figure 6 with (8):

$$
\begin{aligned}
S_{I_{\mathrm{nc}}}= & -\frac{R_{1}^{2}}{R_{D}{ }^{2} \cdot \beta^{2}} \cdot S_{I_{\mathrm{scc}}}+\frac{R_{1}^{2}}{R_{D}{ }^{2}} \cdot S_{I_{\mathrm{ecc}}}-S_{I b_{\text {shot }}} \\
& -\frac{R_{e}{ }^{2} \cdot \beta^{2}-R_{3}^{2}}{R_{D}{ }^{2} \cdot \beta^{2}} \cdot S_{I c_{\text {shot }}},
\end{aligned}
$$

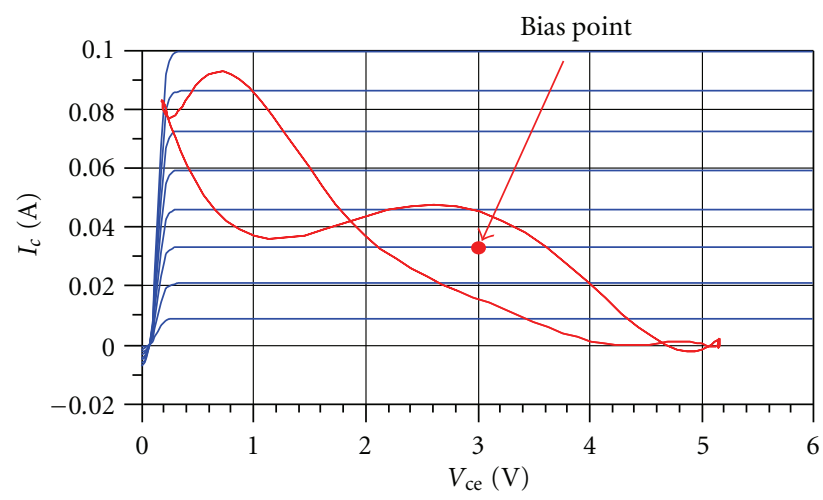

FIgURE 13: Simulation of amplifier load line.

$$
\begin{aligned}
S_{I_{c}}= & -\frac{R_{2}^{2} \cdot R_{1}^{2}}{R_{D}^{2} \cdot R_{\mathrm{be}}^{2} \cdot \beta^{2}} \cdot S_{I_{\mathrm{scc}}}-\frac{R_{4}^{2} \cdot R_{1}^{2}}{R_{D}^{2} \cdot R_{\mathrm{be}}{ }^{2}} \cdot S_{I_{\mathrm{ecc}}} \\
& +\frac{R_{4}^{2} \cdot R_{e}^{2} \cdot \beta^{2}-R_{2}^{2} \cdot R_{3}^{2}}{R_{D}^{2} \cdot R_{\mathrm{be}}^{2} \cdot \beta^{2}} \cdot S_{I_{\mathrm{cshot}}}-\frac{R_{b}^{2}}{R_{\mathrm{be}}^{2}} \cdot S_{I_{r \mathrm{bb}}} \\
& -\frac{R_{e}^{2}}{R_{\mathrm{be}}^{2}} \cdot S_{I_{\mathrm{rbe}}}
\end{aligned}
$$

with

$$
\begin{aligned}
R_{1} & =(\beta+1)\left(R_{\mathrm{be}}+R_{e}\right)+R_{b}, \\
R_{2} & =(\beta+1) \cdot R_{\mathrm{be}}+\beta \cdot R_{e}, \\
R_{3} & =(\beta+1) \cdot R_{\mathrm{be}}+R_{e}+R_{b}, \\
R_{4} & =R_{e}+R_{b}, \\
R_{D}^{2} & =\left[(\beta+1) R_{\mathrm{be}}+\beta R_{e}\right]^{2}-\left(R_{e}+R_{b}\right)^{2} .
\end{aligned}
$$




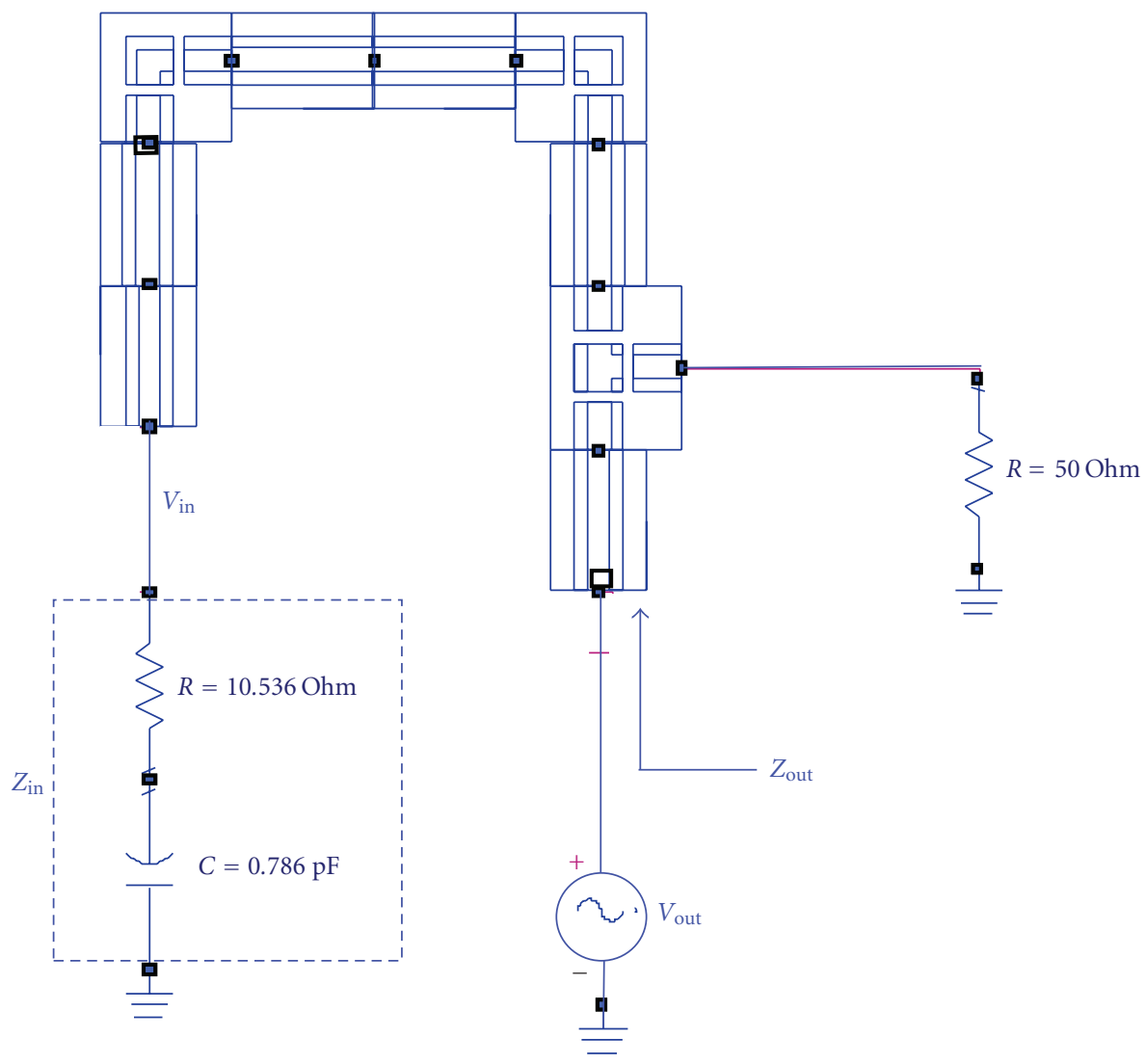

FIgURE 14: Feedback loop circuit.

TABLE 1: $K_{x}$ and $a_{x}$ values of the internal LF noise sources for each frequency.

\begin{tabular}{|c|c|c|c|c|}
\hline \multicolumn{3}{|c|}{$S_{I_{c}}$} & \multicolumn{2}{|c|}{$S_{I_{\mathrm{nc}}}$} \\
\hline Frequency & $a_{I_{c}}$ & $K_{I_{c}}$ & $K_{I_{\mathrm{nc}}}$ & $a_{I_{\mathrm{nc}}}$ \\
\hline $100 \mathrm{~Hz}$ & 2.3 & $6.607 e-11$ & 2.55 & $3.63 e-13$ \\
\hline $1 \mathrm{KHz}$ & 2.33 & $7.9433 e-12$ & 2.39 & $1.585 e-14$ \\
\hline $10 \mathrm{KHz}$ & 2.28 & $7.08 e-13$ & 2.13 & $3.981 e-15$ \\
\hline $100 \mathrm{KHz}$ & 2.36 & $5.012 e-14$ & 1.97 & $1.585 e-17$ \\
\hline
\end{tabular}

In order to limit the LF noise measurement time while obtaining a relatively accurate model, we will only measure the noise sources in the normal, active region where the transistor operates in oscillation condition: the area of the transistor optimum load cycle for low-phase noise operation is defined in [14], by minimizing the LF noise sources conversion. Moreover, some noise measurements have shown that in the area where the base-collector junction is negatively biased, the noise level is independent of $V_{\text {ce }}$. Thus, the measurements will only consist in noise source measurements versus collector current, for a given $V_{\text {ce }}$ close to the transistor bias point for low-phase noise oscillator operation. Following this procedure, Figure 9 shows the spectral densities of the short circuit noise current at transistor access for collector currents $I_{c_{0}}=6.7,13.5,54,108 \mathrm{~mA}$.
TABLE 2: Load pull simulation results.

\begin{tabular}{lcccc}
\hline$P_{e}(\mathrm{~mW})$ & $P_{s}(\mathrm{~mW})$ & $P_{a j \max }(\mathrm{mW})$ & Gain $(\mathrm{dB})$ & $C(\mathrm{~dB})$ \\
\hline 11.56 & 27.1 & 17.6 & 8.2 & 4.3 \\
\hline
\end{tabular}

Then, from (8), the spectral densities $S_{I_{c}}$ and $S_{I_{\mathrm{In}}}$ are computed and plotted versus $I_{c_{0}}$ in log-log plot (Figure 10) for four frequencies $100 \mathrm{~Hz}, 1 \mathrm{KHz}, 10 \mathrm{KHz}$, and $100 \mathrm{KHz}$, which correspond to the frequencies at which oscillators are generally qualified. Note that, from the point of view of the phase noise simulation, these frequencies are independent.

The final step of noise modeling is to determine the spectral density equation of $S_{I_{c}}$ and $S_{I_{\mathrm{nc}}}$ obtained by fitting the curves of (Figure 10) with an equation of the form:

$$
S_{I_{x}}=K_{x} \cdot I_{c}^{a_{x}},
$$

where $I_{c}$ is the collector current, $x$ is taken for nc or $c$.

The values of $K_{x}$ and $a_{x}$ are given in Table 1.

In summary, we extracted the LF noise model of the HBT with internal noise sources. This model was implemented in ADS [15] and will enable us to simulate the phase noise of the oscillator while taking into account the cyclostationary property of noise sources. 


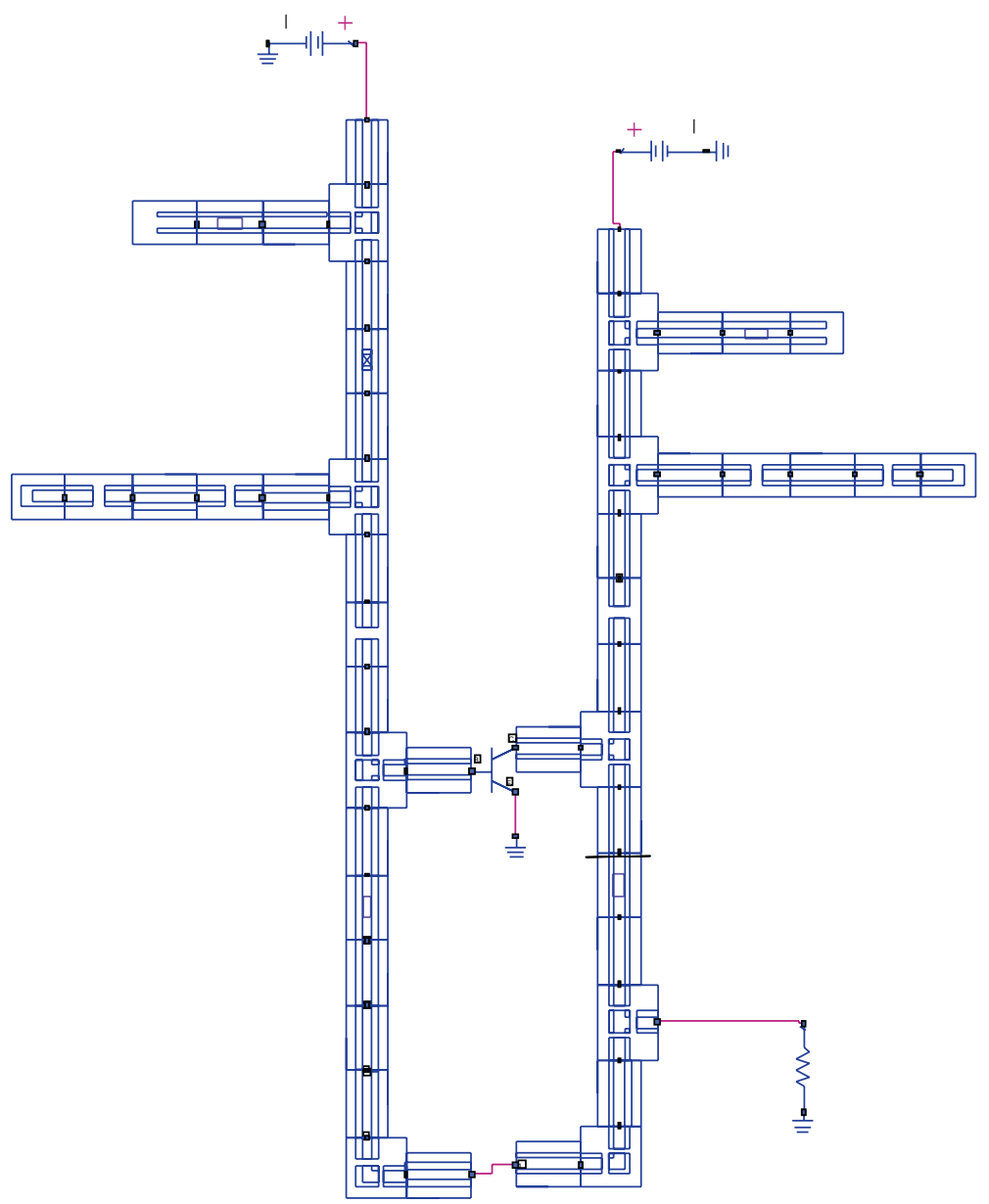

FIGURE 15: First oscillator circuit.

\section{Oscillator Design}

The main objective of this design is to reduce the oscillatorphase noise while retaining a significant output power (few $\mathrm{dbm})$. The desired oscillation frequency is $38 \mathrm{GHz}$ and the MMIC uses the CPW technology. These two goals can be controlled by the intrinsic load cycle form of the transistor in oscillation [14]. This section describes the original design methodology used to reach these objectives by controlling the nonlinear behavior of the transistor when it operates as an oscillator circuit, by means of conventional amplifier nonlinear simulation. Its specific interest is the simulation rapidity and the easy control of the load cycle shaping. Then, by computing the load impedances at transistor input and output and the corresponding voltages, we are able in oscillation to obtain a nonlinear state as close as possible to that obtained in amplifier simulation. For this purpose, the three following steps are necessary.

4.1. Transistor Analysis in Large Signal Amplifier Mode. The schema of the transistor with its bias circuits (in CPW technology) and load impedance (synthesized with an inductor and a resistor in parallel) for nonlinear amplifier simulation is presented in Figure 11.
TABLE 3: Simulated oscillator preformances.

\begin{tabular}{lcccc}
\hline$P_{e}(\mathrm{~mW})$ & $P_{s}(\mathrm{~mW})$ & $P_{a j \max }(\mathrm{mW})$ & Gain $(\mathrm{dB})$ & $C(\mathrm{~dB})$ \\
\hline 13.9 & 50.3 & 7.3 & 5.6 & 4.3 \\
\hline
\end{tabular}

TABLE 4: Contribution of elementary noise sources to total phase noise at $100 \mathrm{kHz}$ from the carrier.

\begin{tabular}{ll}
\hline Total PN noise & $-76.94 \mathrm{dBc} / \mathrm{Hz}$ \\
\hline PN due to source $S_{I c}$ & $-76.94 \mathrm{dBc} / \mathrm{Hz}$ \\
PN due to source $S_{I \mathrm{nc}}$ & $-106.3 \mathrm{dBc} / \mathrm{Hz}$ \\
PN due to shot noise source at collector & $-119.8 \mathrm{dBc} / \mathrm{Hz}$ \\
\hline
\end{tabular}

After some tuning of the bias point and load impedance, the gain, the output, and added powers versus the input power are plotted in Figure 12 and the load cycle in Figure 13.

Thus, we obtain the values given in Table 2 for the following bias points $I_{b_{0}}=1.5 \mathrm{~mA}, V_{\mathrm{ce}_{0}}=2.2 \mathrm{~V}, I_{c_{0}}=$ $35 \mathrm{~mA}$, where $P_{e}$ and $P_{s}$ represent the transistor input and output powers, $C$ the gain compression. Note that to reach a sufficient output power and compression gain (to ensure oscillation after manufacturing despite technological spread), the load cycle must be close to the area where the 

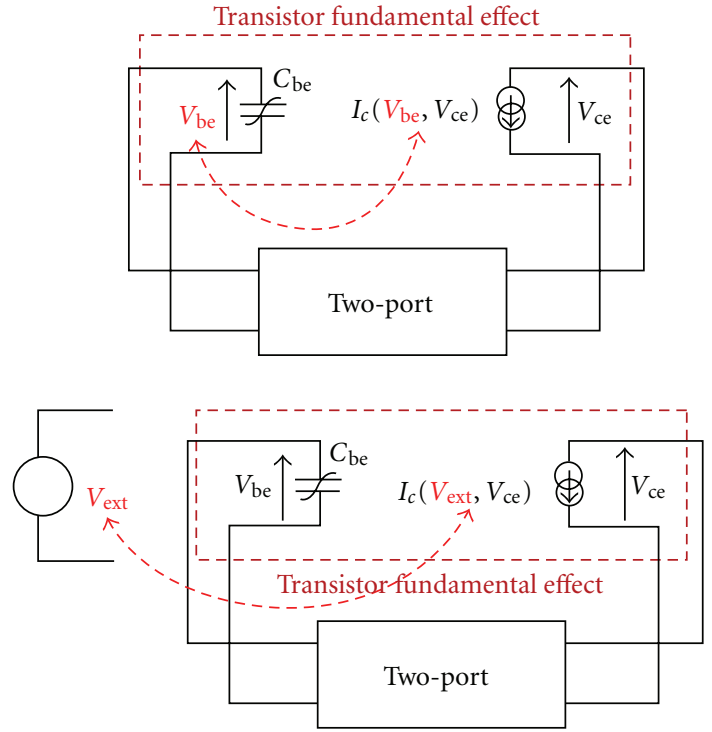

Figure 16: The open loop operation.

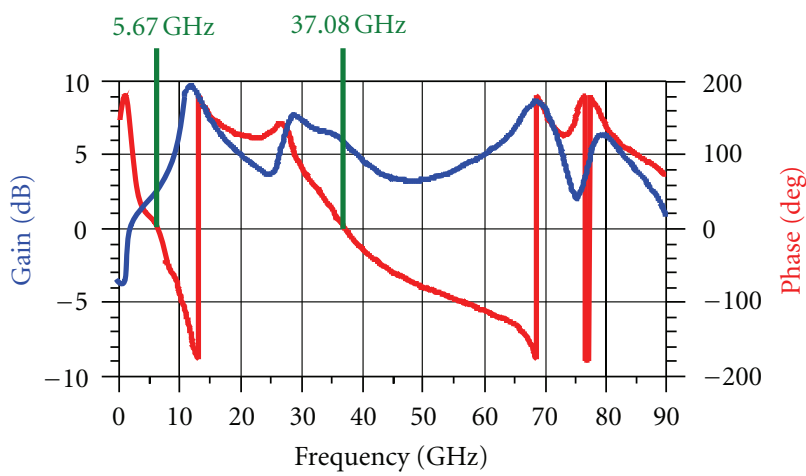

(a)

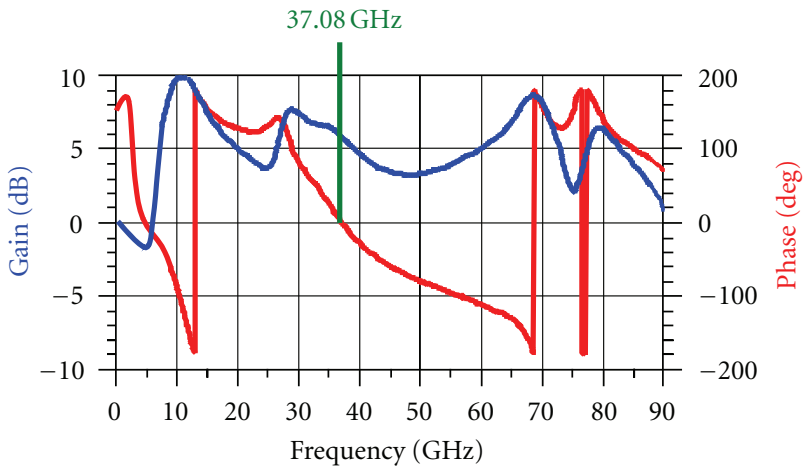

(b)

Figure 17: Magnitude and phase of open loop gain.

base-collector junction conducts. From this simulation, we compute the input and output impedances $Z_{\text {in }}$ and $Z_{\text {out }}$ and voltage gain $G=V_{\text {out }} / V_{\text {in }}$. These data will serve to design the feedback circuit in order to keep this nonlinear state in oscillation as explained in the next section.

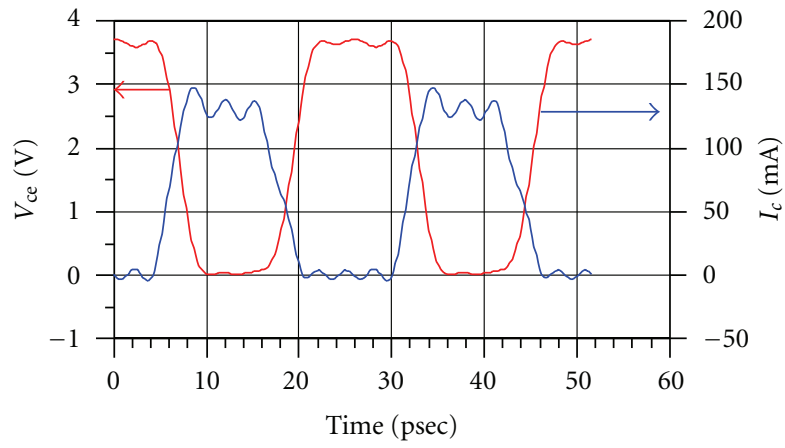

FIGURE 18: Intrinsic time domain waveform of $I_{c}$ current and $V_{\text {ce }}$ voltage.

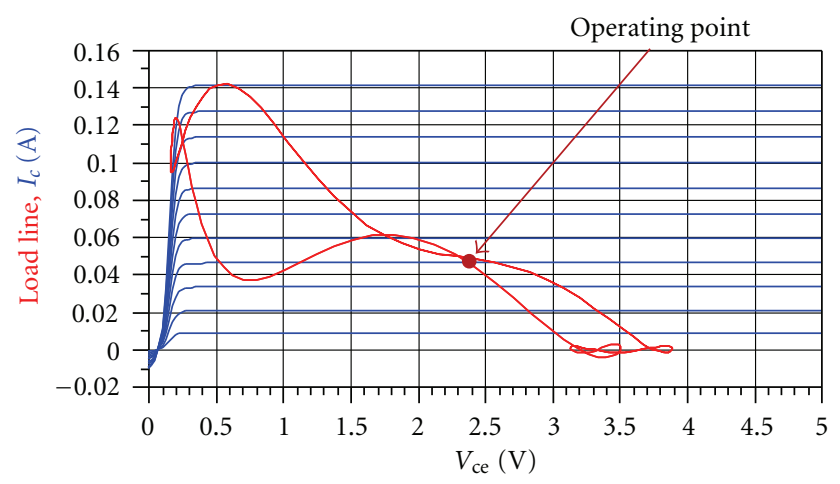

Figure 19: Oscillator intrinsic load line.

TABLE 5: Comparison of oscillator performances.

(a)

\begin{tabular}{lccc}
\hline Technology & $f_{0}(\mathrm{GHz})$ & $\mathrm{TB}(\%)$ & $\mathcal{L}\left\{f_{\text {off } \text { set }}\right\}(\mathrm{dBc} / \mathrm{Hz})$ \\
\hline Si/SiGe [16] & 38 & not & -55 \\
InGaP/GaAs [17] & 40.8 & $<1 \%$ & -95 \\
GaAs [18] & 38 & not & -104 \\
AlInAs/InGaAs [19] & 39 & 9 & -75 \\
AlInAs/InGaAs [20] & 38.1 & $<1 \%$ & -85 \\
InP [21] & 39.9 & $<1 \%$ & -84 \\
\hline InP (this work) & $\mathbf{3 7 . 1}$ & not & $-\mathbf{8 0}$
\end{tabular}

(b)

\begin{tabular}{lcc}
\hline$\Delta f_{\text {of } f \text { set }}(\mathrm{KH} z)$ & $P_{\text {out }}(\mathrm{dBm})$ & $\mathrm{FOM}(\mathrm{dBc} / \mathrm{Hz})$ \\
\hline 100 & 2 & -53.2 \\
100 & 5.3 & -90.5 \\
1000 & 11.9 & -67.3 \\
100 & 5 & -89.5 \\
100 & 8.4 & -76.8 \\
100 & 5 & -79.6 \\
\hline $\mathbf{1 0 0}$ & $\mathbf{5 . 1 8}$ & $-\mathbf{7 4 . 8}$ \\
\hline
\end{tabular}

4.2. Determination of the Feedback Circuit. This step involves the determination of the feedback loop designed with transmission line and of the output circuit (matching circuit) whose schema is given in Figure 14. In this schema, the 


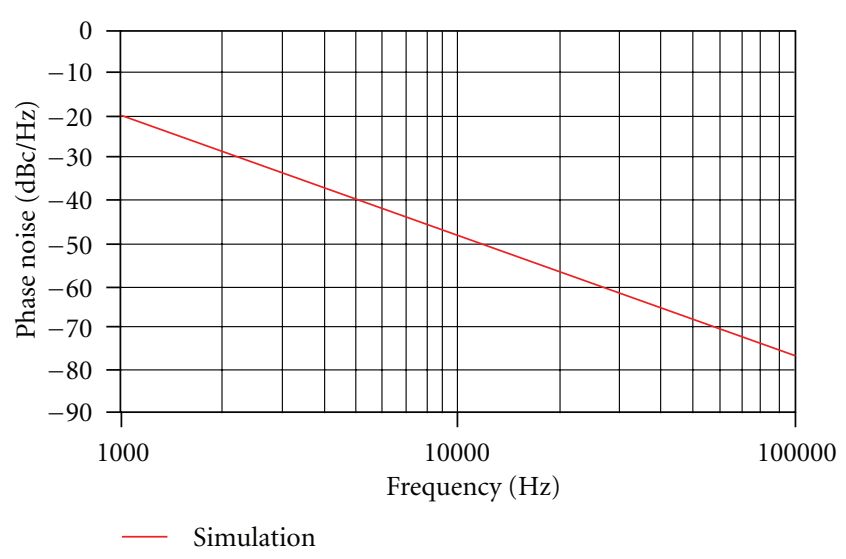

FIgUre 20: Phase noise simulation result.

transistor input impedance $Z_{\text {in }}$ is synthesized with an RC circuit.

The goal of the linear optimization of the line widths and lengths is to obtain the same output impedance $Z_{\text {out }}$ and voltage gain $G=V_{\text {out }} / V_{\text {in }}$ as in the previous section and by taking into account the technology and geometric constraints. Thus, the first draft of the oscillator circuit is given in Figure 15.

4.3. Oscillator Simulation. This section describes all the necessary simulations to ensure good performances of the oscillator (stability, phase noise, etc.). The first simulation is an open-loop simulation [22]. This simulation allows us to determine the starting oscillation frequency and to verify that no other parasitic oscillations exist. In order to open the oscillation loop, a new circuit is drawn (Figure 16): the voltage-controlled current source of the transistor fundamental effect is isolated from the other elements of the transistor model and is now controlled by an external generator $V_{\text {ext }}$. All the other circuit elements are included in the feedback two-port circuit.

Then the open loop gain is defined by

$$
G_{\mathrm{OL}}(\omega)=\frac{V_{\mathrm{be}}(\omega)}{V_{\mathrm{ext}}(\omega)}
$$

The conditions to obtain oscillation starting are given by (12):

$$
\begin{array}{r}
\left|G\left(j \omega_{0}\right) \cdot H\left(j \omega_{0}\right)\right|>1, \\
\arg \left(G\left(j \omega_{0}\right) \cdot H\left(j \omega_{0}\right)\right)=0, \\
\left.\frac{\partial \arg (G(j \omega) \cdot H(j \omega))}{\partial \omega}\right|_{\omega_{0}}<0,
\end{array}
$$

Figure 17(a) shows this simulated open-loop gain for the oscillator circuit of Figure 15. A parasitic oscillation appears at frequency $5.67 \mathrm{GHz}$. An RC series circuit has been added in parallel with the bias circuit to eliminate these oscillations. The new open loop gain is shown in Figure 17(b).
We can note only one starting oscillation frequency at 37.08 GHz. This open-loop analysis also allows to compute the oscillator loaded quality factor with expression (13) [23]:

$$
Q_{\text {Loscill }}\left(\omega_{0}\right)=\left.\frac{\omega_{0}}{2}\left|\frac{d \arg \left(\widetilde{G}_{\mathrm{ol}}(j \omega)\right)}{d \omega}\right|\right|_{\omega_{0}} .
$$

The quality factor obtained by this simulation is equal to 33. Now, we perform a Harmonic Balance simulation of the oscillator. The time domain waveform of $I_{c}$ current and $V_{c e}$ voltage are shown in Figure 18.

The intrinsic load line cycle is shown in Figure 19.

Finally, the oscillator electrical performances are detailed in Table 3.

The simulation of the oscillator phase noise $(\mathrm{PN})$ is shown Figure 20.

Table 4 presents the contribution of elementary noise sources of the internal transistor at the $100 \mathrm{KHz}$ frequency.

The final layout, taking into account all the technological constraints, including stabilizing circuits and a $3 \mathrm{~dB}$ attenuator at the output to reduce pulling effect, is shown Figure 21. The circuit was fabricated by III-V Lab.

\section{Oscillator Measurement}

5.1. Power and Oscillation Frequency Measurement. To test the robustness of the oscillation, measurements have been performed on 15 oscillators of the wafer for various DC $I_{c}$ currents. Figure 22 presents the oscillation frequency and the output power versus $I_{c_{0}}$ current for different $V_{\mathrm{ce}_{0}}$ voltages and a $V_{\text {be }_{0}}$ voltage equal to $0.8 \mathrm{~V}$.

The output power increases by $5 \mathrm{~dB}$ over the variation range of $I_{c_{0}}$, while the oscillation frequency shows a variation of $1 \mathrm{GHz}$ over the same range. This shows that the oscillation frequency remains stable for an $I_{\mathcal{c}_{0}}$ current variation between 35 and $60 \mathrm{~mA}$.

5.2. Phase Noise Measurement. The XLIM Laboratory has an AEROFLEX PN9500 bench (Figure 23) to perform the phase noise measurement of the oscillator. This bench enables us measure the phase noise of the oscillator in the $250 \mathrm{MHz}-$ 26.5 GHz bandwidth with down-converter. The oscillation frequency of the circuit being out of range, we developed our own down-converter to reduce the oscillation frequency in the PN9500 bandwidth. Thus, the system using the delay line method is presented Figure 24.

It is composed of a mixer in which an LO signal at frequency $10.75 \mathrm{GHz}$ is generated by a high spectral purity synthesizer PN9276-20 from the PN9500 setup bench. The RF signal comes from the measured oscillator. The IF output is connected to the PN9718 input. Before measuring the oscillator phase noise, we must ensure that the measurement chain will not add noise. To do that, we replace the oscillator by a high spectral purity synthesized source (ANRITSU 68367C). The phase noise of the system measured with this source is represented in Figure 25 and gives the noise floor of the system. 


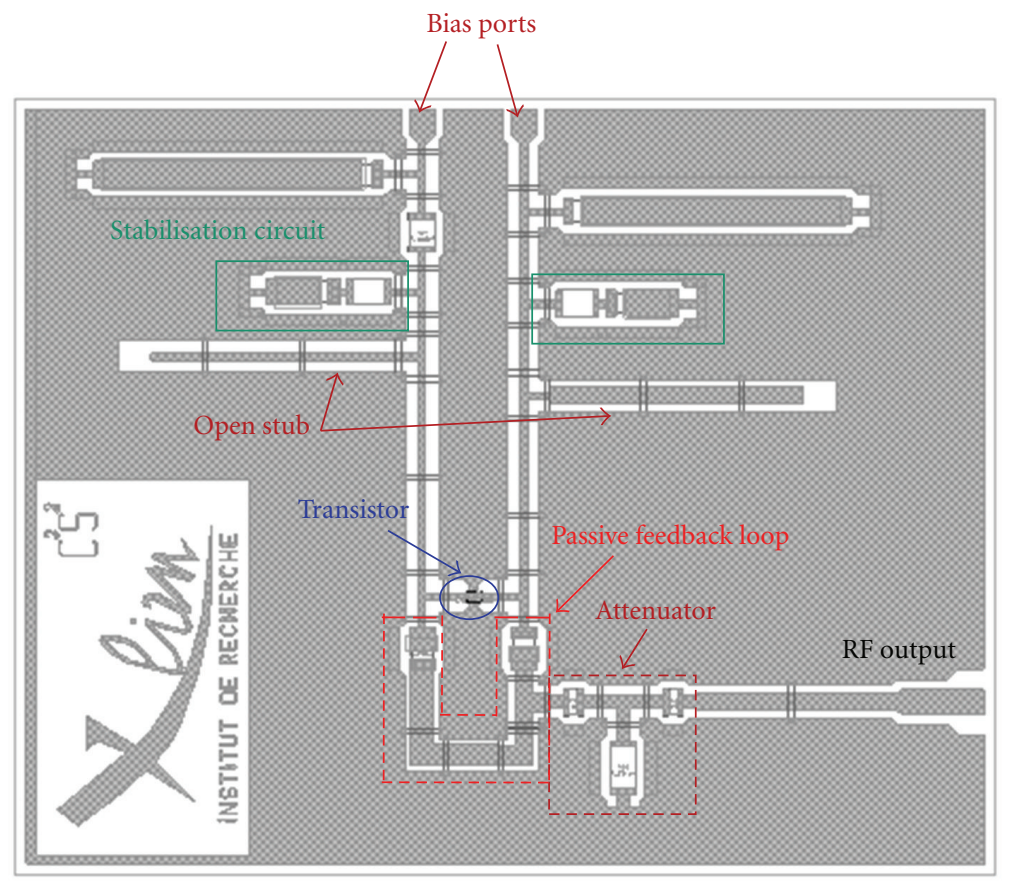

Figure 21: Oscillator layout $\left(2070 \times 1635 \mu \mathrm{m}^{2}\right)$.

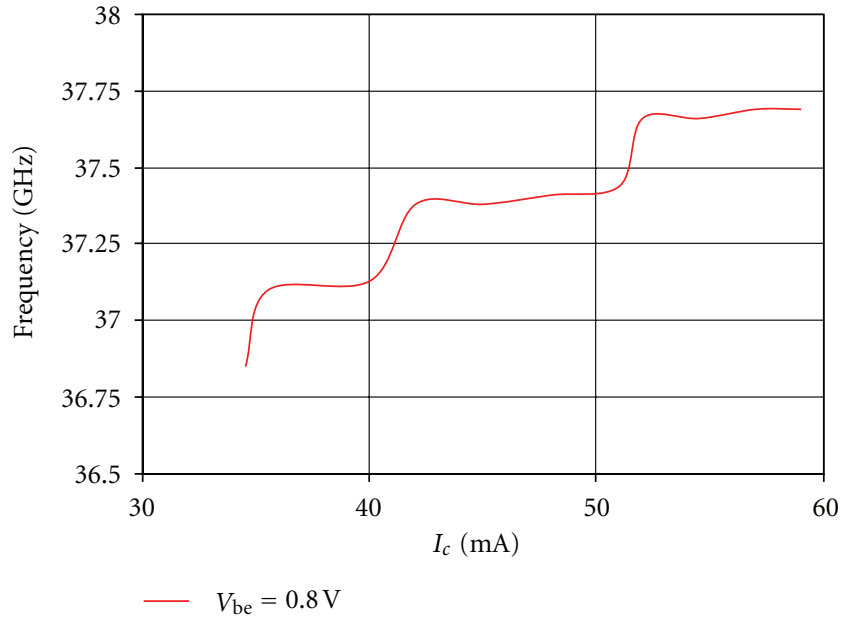

(a)

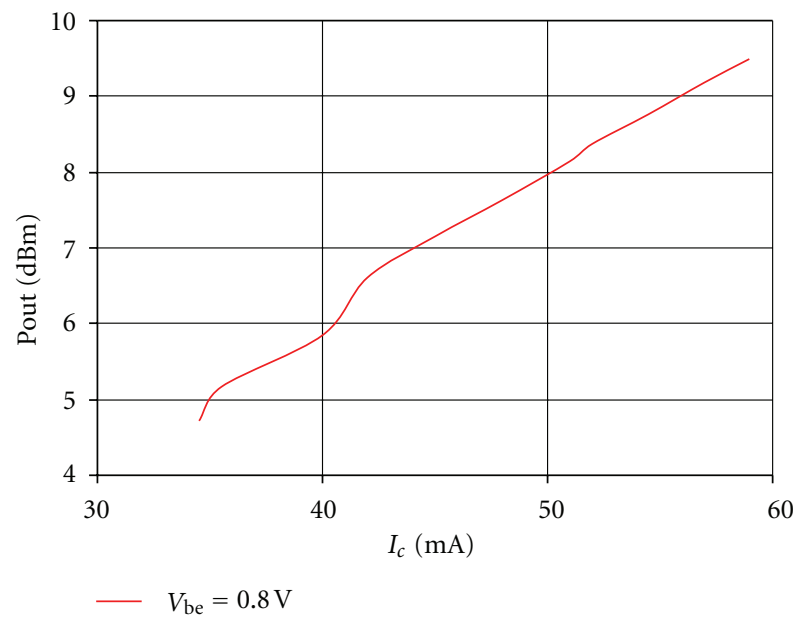

(b)

Figure 22: Measurement result of oscillation frequency and output power versus $I_{c}$ current for $V_{\text {be }}$ voltage equal to $0.8 \mathrm{~V}$.

Figure 26 shows the plot of the phase noise measurement of the 15 oscillators on the wafer and the simulated phase noise for the bias point $V_{\mathrm{be}_{0}}=0.8 \mathrm{~V}$ and $V_{\mathrm{ce}_{0}}=2.2 \mathrm{~V}$.

We can note that the phase noise simulation coincides with the average results of measurement. The oscillation frequency measurement for the nominal bias point is close to $37.1 \mathrm{GHz}$ with an output power equal to $5.2 \mathrm{Bm}$. The phase noise measure is much higher than the system PN floor ( $>15 \mathrm{~dB}$ ), so we can confirm that the phase noise is that of the oscillator. To compare our oscillator with published oscillators with an oscillation frequency close to $38 \mathrm{GHz}$, we will use a figure of merit described by (14):

$$
\begin{aligned}
\text { FOM }= & \mathcal{L}\left\{f_{\text {of } f \text { set }}\right\}-20 \log \left(\frac{f_{0}}{f_{\text {ref }}}\right)-25 \log \left(\frac{f_{\text {of } f \text { set }} \text { ref }}{f_{\text {of } f \text { set }}}\right) \\
& -20 \log \left(\frac{\text { TB } \%}{100}\right)-10 \log \left(\frac{P_{\text {out }}}{1 \mathrm{~mW}}\right)
\end{aligned}
$$

where $\mathcal{L}\left\{f_{\text {of } f \text { set }}\right\}$ is the oscillator phase noise at a frequency offset from carrier $f_{\text {of } f \text { set. }}$ The oscillation frequency of the 


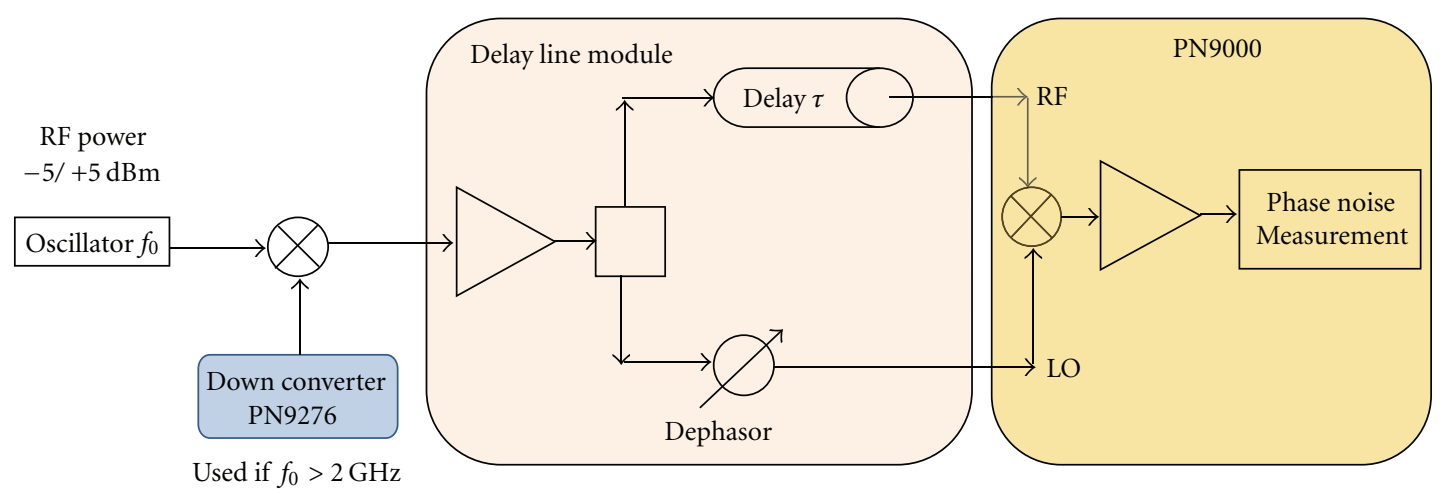

FIgURE 23: Synoptic of PN9500 phase noise bench.

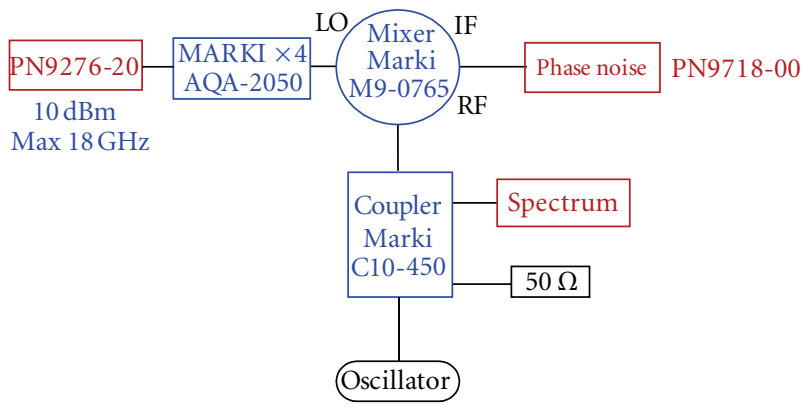

FIGURE 24: Principle of realized phase noise bench.

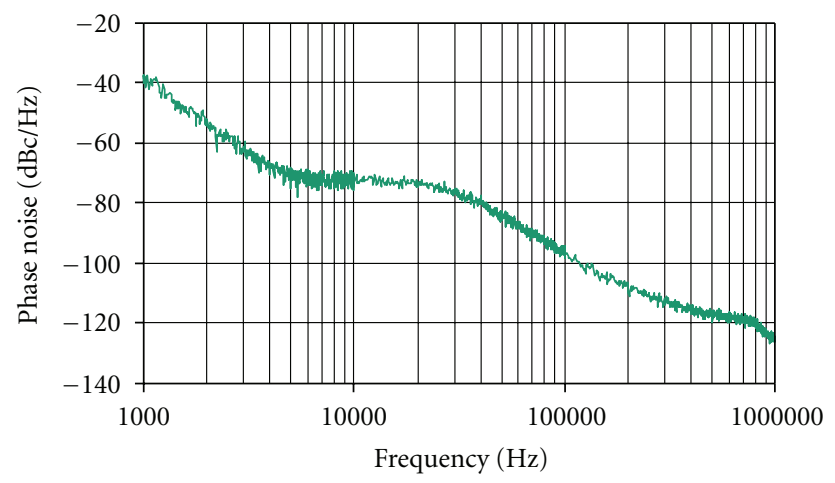

Figure 25: PN floor of the system.

various oscillators $\left(f_{0}\right)$ is reduced to a reference frequency $\left(f_{\text {ref }}=37.1 \mathrm{GHz}\right)$ which is the oscillation frequency of the oscillator of this work. The carrier frequency offset is reduced to a distance $f_{\text {off } f \text { set }_{\text {ref }}}=100 \mathrm{KHz}$. The multiplier factor is equal to 25 because the oscillator phase noise of this work has a slope of $-25 \mathrm{~dB} /$ decade. The tuning bandwidth TB (in percentage) is also taken into account. The oscillator output power $P_{\text {out }}$ is reduced to a reference of $1 \mathrm{~mW}$. This figure of merit is valid for oscillator with a tuning bandwidth of more than 1\%: otherwise, these oscillators are considered as fixed-frequency oscillators. The results are summarized in Table 5 . We have chosen a value of phase noise of $-80 \mathrm{dBc} / \mathrm{Hz}$ which corresponds to an average value of all those measured.

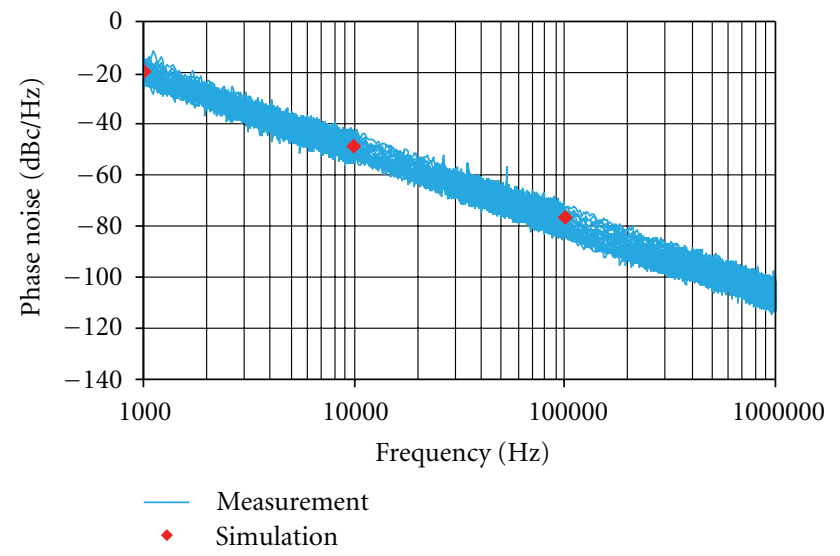

FIgURE 26: Comparison between measurement and simulation of oscillator phase noise.

We can verify that we obtain an average performance as regarding the figure of merit compared to those published.

\section{Conclusion}

In conclusion, this work enables us to build an MMIC Kaband oscillator with good performances. An electrothermal nonlinear model of the transistor was proposed, including cyclostationary noise sources to accurately predict its phase noise. The design method used allowed us to define a nonlinear operation of the transistor to limit the contributions of low-frequency noise sources responsible for the phase noise. This amplifier nonlinear state has been kept in oscillation operation. This evaluation of the III-V Lab process has given encouraging results concerning the feasibility of efficient Kaband circuits.

\section{Acknowledgment}

The authors thank to Philippe Berdaguer for his participation to the technological process of circuits fabrication. Support from the French National Research Agency (Agence Nationale pour la Recherche) through the ANR/pNano ATTHENA program is gratefully acknowledged. 


\section{References}

[1] J. Godin, V. Nodjiadjim, M. Riet et al., "V-band amplifier MMICs using multi-finger InP/GaAsSb DHBT technology," in Proceedings of the Compound Semiconductor Integrated Circuit Symposium, pp. 1-4, October 2009.

[2] M. Riet, V. Nodjiadjim, A. Scavennec et al., "InP/GaAsSb/InP multifinger DHBTs for power applications," in Proceedings of the 20th International Conference on Indium Phosphide and Related Materials, pp. 1-3, May 2008.

[3] H. Gummel and H. Poon, "A compact bipolar transistor mode," in Proceedings of the Solide-State Circuits Conference Digest of Technical Papers, vol. 13, pp. 78-79, 1970.

[4] O. Jardel, R. Quere, S. Heckmann et al., "An electrothermal model for GaInP/GaAs power HBTs with enhanced convergence capabilities," in Proceedings of the European Microwave Integrated Circuits Conference, pp. 296-299, Manchester, UK, September 2006.

[5] T. Peyretaillade, M. Perez, S. Mons et al., "A pulsed measurementbased electrothermal model of HBT with thermal stability prediction capabilitie," in Proceedings of the Microwave Symposium Digest, vol. 3, pp. 1515-1518, Denver, Colo, USA, June 1997.

[6] S. Heckmann, R. Sommet, J.-M. Nebus et al., "Characterization and modeling of bias dependent breakdown and selfheating in GaInP/GaAs power HBT to improve high power amplifier design," IEEE Transactions on Microwave Theory and Techniques, vol. 50, no. 12, pp. 2811-2819, 2002.

[7] S. Laurent, G. Callet, J.-C. Nallatamby, M. Prigent, V. Nodjiadjim, and M. Riet, "Nonlinear model of inp/gaassb/inp dhbt process for design of a q-band mmic oscillator," in Proceedings of the European Microwave Integarted Circuits, pp. 270-273, September 2010.

[8] R. H Winckler, "Thermal properties of high power transistors," IEEE Transactions on Electron Devices, vol. 14, pp. 260 263, 1967.

[9] A. Liboa De Souza, J.-C. Nallatamby, M. Prigent et al., "A methodology to characterize the low-frequency noise of InP based transistors," in Proceedings of the Microwave Integrated Circuit Conference (EuMIC '08), pp. 123-126, October 2008.

[10] A. L. De Souza, J.-C. Nallatamby, M. Prigent, and J. Obregon, "On the cyclostationary properties of the $1 / \mathrm{f}$ noise of microwave semiconductor devices," in Proceedings of the IEEE MTT-S International Microwave Symposium Digest, pp. 1569 1572, June 2008.

[11] J.-C. Nallatamby, M. Prigent, M. Camiade, A. Sion, C. Gourdon, and J. J. Obregon, "An advanced low-frequency noise model of GaInP-GaAs HBT for accurate prediction of phase noise in oscillators," IEEE Transactions on Microwave Theory and Techniques, vol. 53, no. 5, pp. 1601-1611, 2005.

[12] I. Getreu, Modeling The Bipolar Transistor, Tektronix, 1976.

[13] A. Lisboa de Souza, J.-C. Nallatamby, M. Prigent et al., "Low-frequency noise measurements of bipolar devices under high DC current density: whether transimpedance or voltage amplifiers," in Proceedings of the European Microwave Integrated Circuits Conference, pp. 114-117, September 2006.

[14] J.-C. Nallatamby, M. Prigent, and J. Obregon, "From large signal transistor noise sources modelling to the design of low phase noise oscillator circuits," in Proceedings of the 28th European Microwave Conference Workshop on Non-linear Device Models and Low Phase-Noise Oscillator Design, 2006.

[15] C. Gourdon, J.-C. Nallatamby, D. Baglieri, M. Prigent, M. Camiade, and J. Obregon, "Accurate design of HBT VCOs with flicker noise up-conversion minimization, using an advanced low-frequency cyclostationary noise model," in Proceedings of the IEEE MTT-S International Microwave Symposium Digest, pp. 1519-1522, 2005.

[16] C. Rheinfelder, F. Beisswanger, J. Gerdes et al., "A coplanar 38-GHz SiGe MMIC oscillator," IEEE Microwave and Guided Wave Letters, vol. 6, no. 11, pp. 398-400, 1996.

[17] M. Heins, D. Barlage, M. T. Fresina et al., "Low phase noise Ka-band VCOs using InGaP/GaAs HBTs and coplanar waveguide," in Proceedings of the IEEE Radio Frequency Integrated Circuits Symposium (RFIC '97), pp. 215-218, June 1997.

[18] K. Hosoya, S. Tanaka, Y. Amamiya, T. Niwa, H. Shimawaki, and K. Honjo, "RF HBT oscillators with low-phase noise and high-power performance utilizing $(\lambda / 4 \pm \delta)$ open-stubs resonator," IEEE Transactions on Circuits and Systems I, vol. 53, no. 8, pp. 1670-1682, 2006.

[19] A. Kurdoghlian, M. Mokhtari, C. H. Fields et al., " 40 GHz fully integrated and differential monolithic VCO with wide tuning range in AIInAs/InGaAs HBT," in Proceedings of the IEEE GaAs Digest, pp. 129-132, October 2001.

[20] K. Tanji, T. Kaneko, Y. Amamiya et al., "A $38 \mathrm{GHz}$ low-phase noise monolithic VCO For FM MOD using an AlGaAs/InGaAs HBT with $\mathrm{p}+/ \mathrm{p}$ regrown base contacts," in Proceedings of the 28th European Microwave Conference, pp. 47-51, 1998.

[21] H. Wang, K. W. Chang, L. Tran et al., "Low phase noise millimeter-wave frequency sources using InP-based HBT MMIC technology," IEEE Journal of Solid-State Circuits, vol. 31, no. 10, pp. 1419-1424, 1996.

[22] M. Odyniec, RF and Microwave Oscillator Design, ARTECH HOUSE, 2002, Edited by A. House.

[23] T. Ohira, "Rigorous Q-factor formulation for one- and twoport passive linear networks from an oscillator noise spectrum viewpoint," IEEE Transactions on Circuits and Systems II: Express Briefs, vol. 52, no. 12, pp. 846-850, 2005. 

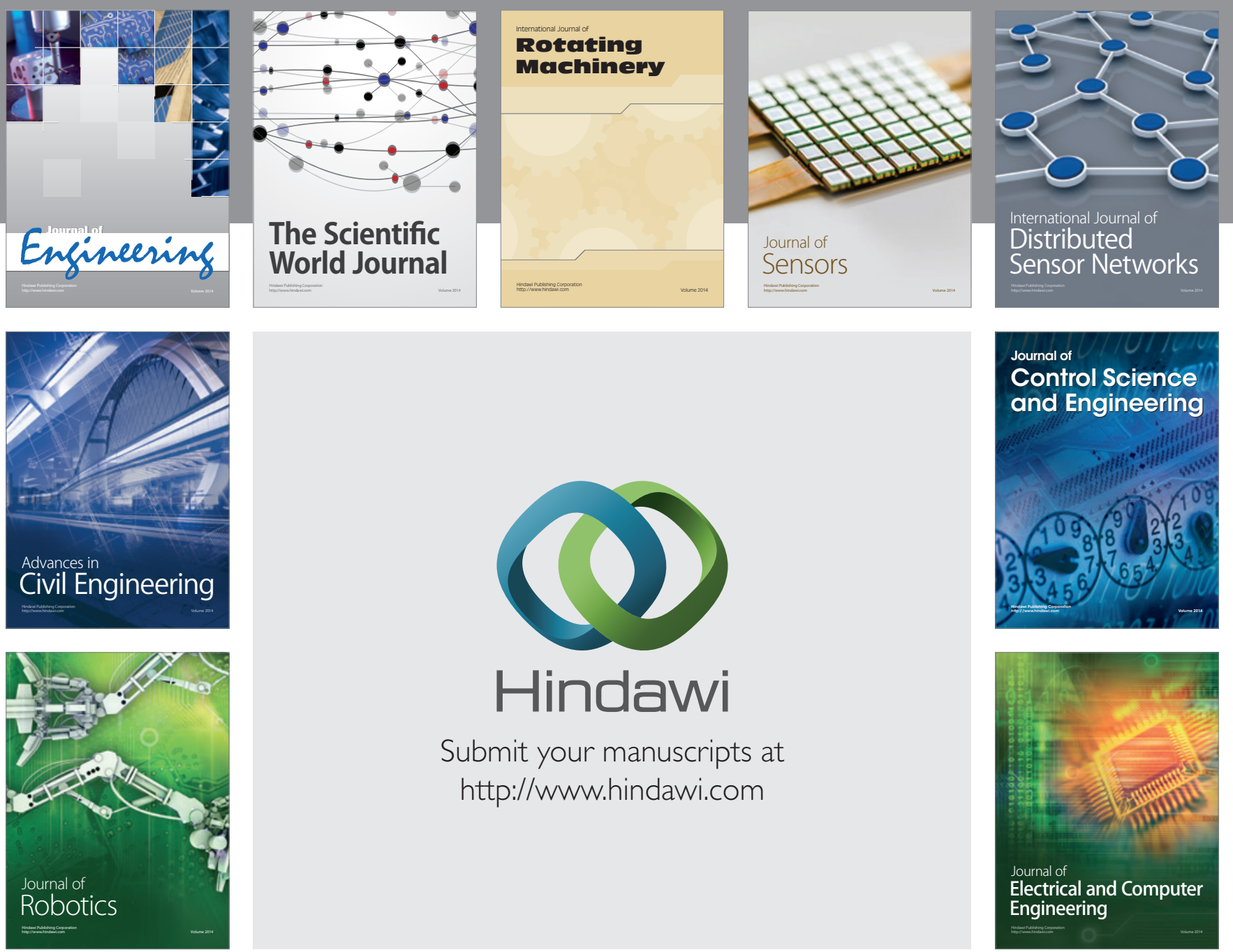

Submit your manuscripts at

http://www.hindawi.com
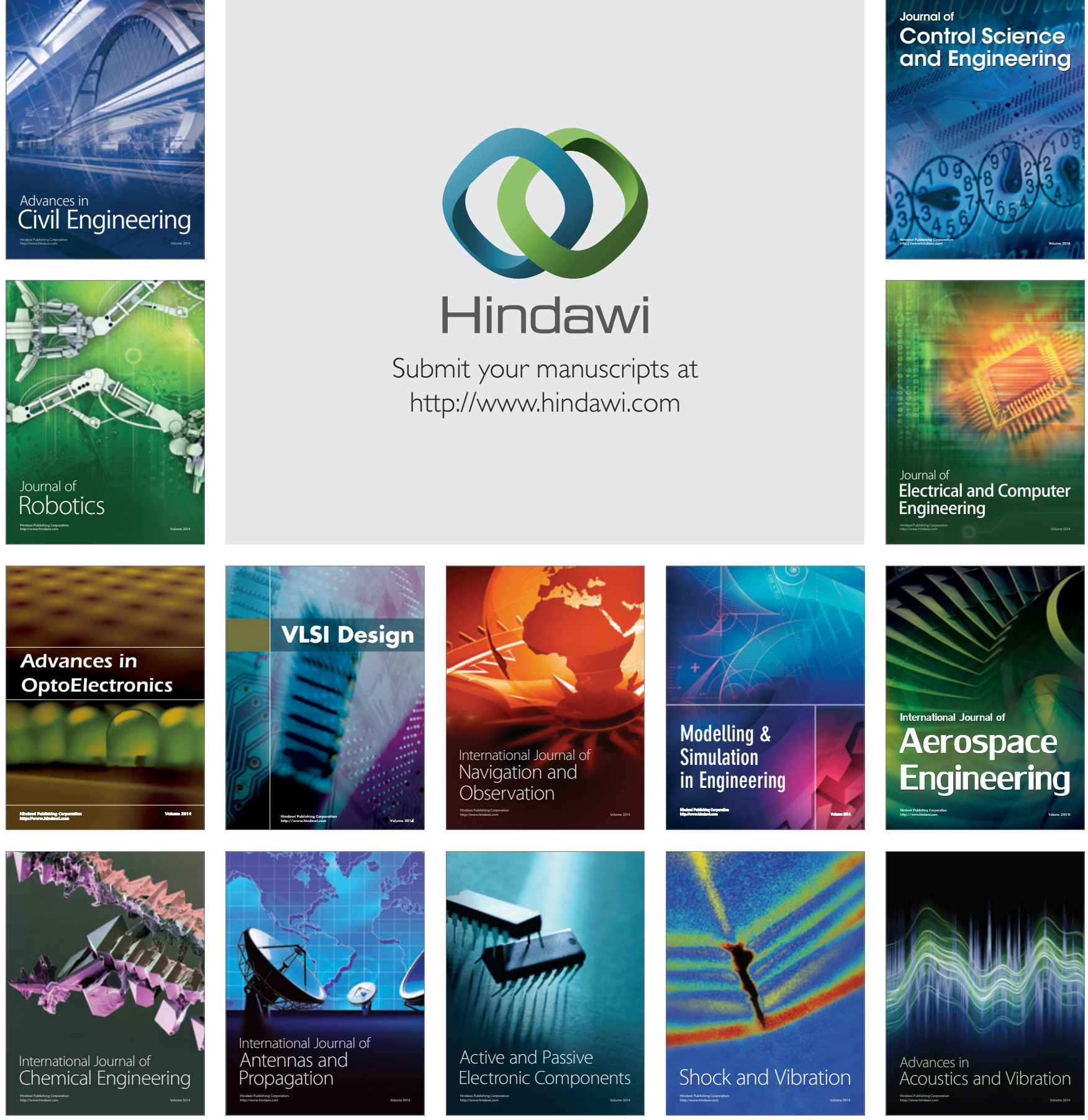